\title{
MÉTODO E APLICAÇÕES DA ABORDAGEM DIREITO E POLÍTICAS PÚBLICAS (DPP)
}

\section{METHOD AND APPLICATIONS OF THE LAW AND PUBLIC POLICY (LPP) APPROACH}

\author{
MARIA PAULA DALLARI BUCCI ${ }^{1}$
}

RESUMO: A despeito da multiplicação de trabalhos relacionando Direito e Políticas Públicas, a falta de uma abordagem estruturada limita o desenvolvimento do conhecimento acumulado, reverberando a dispersão de ângulos de visão e temáticas (seção 1). Esse limite enseja reflexão sobre questões de método para a abordagem Direito e Políticas Públicas (DPP), seu objeto, em vista de que sujeito. Superá-lo pressupõe referências comuns e procedimentos de pesquisa generalizáveis, que façam sentido para uma comunidade de pesquisadores e lhe permitam evoluir como conjunto (seção 2). O objeto da abordagem DPP constitui a ação estatal nas políticas públicas, ação governamental coordenada e em escala ampla sobre problemas complexos. Examina-se bibliografia estrangeira específica sobre Direito e Políticas Públicas, dos anos 1990, momento em que essa conexão surge (seção 3). Em seguida, revisa-se o sentido das políticas públicas na construção do Estado social brasileiro pós-1988, refutando que se trate de expediente de despolitização que se desvia das transformações estruturais necessárias à quebra do subdesenvolvimento (seção 4). Finalmente, mapeiam-se aptidões analíticas como base para uma matriz de métodos, em três vertentes: 1) temas mais afeitos à abordagem DPP, tais como questões de direito material e organização jurídica próprias dos direitos sociais (educação, saúde, assistência social, segurança etc.), infra-estrutura, problemas urbanos e outras; 2) padrões de controle jurídico de políticas públicas que vêm sendo desenvolvidos por magistratura, Ministério Público, Advocacia Pública, Defensoria Pública e Tribunais de Contas; 3) combinações da abordagem DPP com os campos disciplinares tradicionais, como Direito Administrativo, Constitucional e Processual (seção 5).

Palavras-Chave: Abordagem Direito e Políticas Públicas; Método; Ação estatal; Estado social.

\footnotetext{
${ }^{1}$ Professora da Faculdade de Direito da Universidade de São Paulo (USP). Doutora e Livre-Docente pela mesma instituição. E-mail: mariapaula@usp.br. Currículo Lattes: http://lattes.cnpq.br/5277262878389044. ORCID n. 0000-0003-2862-8986. A autora agradece os comentários dos integrantes do Grupo de Pesquisa Estado, Direito e Políticas Públicas, bem como dos alunos da disciplina de pós-graduação Direito e Políticas Públicas: Método e Aplicações (2019) às versões iniciais deste texto.
} 
AbStRACT: Despite the multiplication of papers relating Law and Public Policy, the lack of a structured approach limits the development of accumulated knowledge, reverberating the dispersion of viewing angles and themes (section 1). This limit gives rise to reflection on method issues for the Law and Public Policy (LPP) approach, its object, in view of which subject. Overcoming it presupposes common references and generalizable research procedures that make sense for a research community and allow it to evolve as a whole (section 2). The object of the DPP approach is state action in public policy, coordinated and large-scale government action on complex problems. A specific foreign bibliography on law and public policy from the 1990s is examined, at which time this connection arises (section 3). Then, we review the meaning of public policies in the construction of the Brazilian social state after 1988, refuting that it is a depoliticization device that deviates from the structural transformations necessary to break underdevelopment (section 4). Finally, analytical skills are mapped as the basis for a matrix of methods, in three strands: 1) themes more in line with the LPP approach, such as issues of material law and legal organization specific to social rights (education, health, social assistance, security etc.), infrastructure, urban and other problems; 2) standards of legal control of public policies that have been developed by the judiciary, the Public Prosecution Service, the Public Advocacy, the Public Defender and the Courts of Auditors; 3) combinations of the LPP approach with traditional disciplinary fields such as Administrative, Constitutional and Procedural Law (section 5).

Keywords: Law and Public Policy Approach; Method; State action; Social state.

\section{Direito e Políticas Públicas: uma ABordagem, NÃo UM CAMPo}

A abrangência da abordagem Direito e Políticas Públicas² (DPP) registra considerável ampliação nos últimos anos. Mas o aumento do volume e qualidade dessa produção, embora evidencie o seu objeto e núcleo de sentido - a ação governamental coordenada e em escala ampla, atuando sobre problemas complexos, a serviço de uma estratégia informada por elementos jurídicos (e não jurídicos) - não resulta necessariamente em condições mais propícias ao seu desenvolvimento. Ao contrário, a falta de um tratamento sistemático ou estruturado tende a reverberar a dispersão de ângulos de visão e temáticas, o que dificulta o aproveitamento coletivo do conhecimento acumulado. Esse limite enseja

\footnotetext{
${ }^{2} \mathrm{O}$ léxico na área de políticas públicas, em português como em língua inglesa, é uma fonte particular de problemas, a começar pelas distinções essenciais entre politics e policies. Adota-se aqui a locução políticas públicas, no plural, visto ser a mais utilizada no vocabulário corrente para designar o gênero de que trata o artigo. A expressão no singular comumente designa uma política pública em especial.
} 
reflexão sobre as questões de método ${ }^{3}$ para a abordagem de DPP, que busque compreender o seu objeto, em vista de que sujeito, bem como os problemas mais afeitos a essa abordagem e com que instrumental. Esse é o caminho para o estabelecimento de referências comuns e procedimentos de pesquisa generalizáveis, que façam sentido para uma dada comunidade de pesquisadores e assim lhe permitam evoluir como conjunto.

Adota-se como premissa que a aplicação das relações entre Direito e Políticas Públicas deve se organizar como abordagem e não como campo ou subcampo no Direito. Importante justificar o sentido dessa opção metodológica, adotada há algum tempo também por outros pesquisadores da área (BUCCI, 2013, p. 11; BUCCI; COUTINHO, 2017, p. 316), na medida em que ela vai em sentido contrário ao que vem ocorrendo em áreas afins, como a chamada Análise de Políticas Públicas, que se destacou da Ciência Política, para, juntamente com a Administração Pública, dar origem a um novo "campo de públicas" (FARAH, 2016), em processo de institucionalização.

Seguindo essa linha, há quem proponha o subcampo interdisciplinar Law and Public Policy 4 , como é o caso de Kreis e Christensen - cabendo registrar que se trata de autores sem formação jurídica, embora atuando em cursos multidisciplinares. Isso talvez contribua para minimizar a percepção dos autores acerca dos problemas dessa opção, como indica a apresentação de algumas dificuldades do relacionamento interdisciplinar:

O subcampo do direito e políticas públicas é um campo dinâmico e interdisciplinar, que tem grande apelo sobre estudiosos, gestores públicos e stakeholders num largo espectro de áreas substantivas, como a regulação dos mercados financeiros, bem estar social e desenho institucional. [...] Mas com esse apelo interdisciplinar [...] vêm também contrastes gritantes nas aproximações conceituais e metodológicas utilizadas no subcampo.

Às vezes essas diferentes visões refletem a natureza do objeto, em outras as variações refletem o treinamento acadêmico do autor. Autores com graduação em direito podem estar mais confortáveis entrando em controvérsias doutrinais e interpretação de textos legais que emergem da promulgação da política, que fazem os não advogados estremecerem. Do mesmo modo, aqueles com formação jurídica podem ficar frustrados diante de números, tabelas e asteriscos indicando significação estatística, que são as marcas

${ }^{3}$ Algumas reflexões sobre o problema do método e suas estratégias constam do cap. 4 de BUCCI (2013).

${ }^{4}$ A expressão em inglês foi mantida para facilitar a diferenciação entre o subcampo proposto por Kreis e Christensen e a abordagem Direito e Políticas Públicas defendida neste artigo. 
registradas da ciência política e da disciplina de políticas públicas - a análise empírica. (KREIS e CHRISTENSEN, 2013, p. 38) ${ }^{5}$

Os autores reconhecem a falta de consenso a respeito do que seja Law and Public Policy na bibliografia e nas revistas sobre o tema, que ora se centram no debate sobre o papel e o poder dos tribunais como policymakers, ora revelam disputas entre juristas tradicionais e estudiosos de Direito e Políticas Públicas, ora expressam a divisão entre os especialistas em Direito Público, de um lado, e em Políticas Públicas, de outro. E concluem: "Apesar das afinidades entre essas visões, a falta de uma abordagem unificada torna difícil traçar fronteiras claras para esse subcampo." (KREIS e CHRISTENSEN, 2013, p. 39) Ainda assim, ensaiam uma definição, procurando reunir seu propósito central, aspecto substantivo e diversidade metodológica, nos seguintes termos:

O subcampo de direito e políticas públicas foca nos problemas de política [policy problems] e no intercâmbio de (i) opções políticas moldadas de forma discricionária, por meio de instrumentos jurídicos (e.g. constitucionais, legais, regulatórios e judiciais), para tratar de problemas políticos e sociais; (ii) práticas administrativas (procedimentos e rotinas); e (iii) impactos sociais, políticos, jurídicos e econômicos. Uma abordagem de direito e políticas públicas reflete esse intercâmbio e se adequa a ele tanto prática como academicamente. Uma abordagem de direito e políticas públicas é aberta tanto a uma gama de disciplinas isoladas como ao trabalho multidisciplinar; ela é, por isso, propícia ao tratamento normativo, empírico e teórico. (KREIS e CHRISTENSEN, 2013, p. 41)

Essa proposta traz interessante roteiro metodológico, mas a ideia de subcampo, no qual estariam contidas as vertentes de problemas elencados pelos autores é um começo, não bastando para explicar por que razão alguém abandonaria o campo disciplinar em que foi formado e está confortavelmente estabelecido, em prol de um novo subcampo, cujos contornos permanecem bastante vagos. Por isso parece mais profícua a abordagem Direito e Políticas Públicas - como essa plataforma epistêmica mencionada pelos autores, "aberta tanto a uma gama de disciplinas isoladas como ao trabalho multidisciplinar" - do que a concepção de campo ou subcampo.

Esse destaque disciplinar, visto por muitos como evolução do "campo de públicas", conforme Marta Farah, professora de Administração Pública, é resultado de um movimento intencional em direção à autonomia científica, baseado em

\footnotetext{
${ }^{5}$ As traduções contidas no artigo são minhas, exceto quando informado de forma diversa.
} 
"disputa e conflito para a delimitação do campo", sem os quais não se afirmaria sua identidade epistêmica.

(...) para que uma disciplina ou campo disciplinar se institucionalize, é preciso que haja delimitação de um objeto específico, distinto do abordado por outras disciplinas. Um segundo elemento necessário à institucionalização de uma disciplina ou campo é a existência de articulação entre ideias e um suporte material, que inclui instituições, revistas e controle de recursos estratégicos. Um terceiro requisito, destacado pela perspectiva da comunidade discursiva, é a existência de articulação de atores em torno de uma agenda e a constituição de um discurso comum, que possibilita a troca de ideias, a criação de fóruns de debate e o desenvolvimento de uma identidade que legitima e dá credibilidade à ação de seus integrantes (OSPINA BOZZI, 1998). É central, ainda, ao conceito de campo, o reconhecimento da existência de disputa e de conflito para a delimitação do campo e entre atores do próprio campo. O conceito de campo científico se contrapõe ao de comunidade científica, proposto por Kuhn (1970), que supunha uma comunidade orientada para o interesse da ciência. (FARAH, 2016, p. 961)

Isso combinado, evidentemente, com a adoção de práticas de pesquisa comuns e convenções metodológicas que expressem o sentido da delimitação estabelecida. Mas as disputas disciplinares, quando a razão de ser do novo campo não é clara, podem não ser fecundas, especialmente se se está diante de problemas e soluções que requerem múltiplas especialidades. As controvérsias que cercaram a criação do Direito Econômico, área bastante afim à análise das políticas públicas (COUTINHO, 2016), ilustram a recomendação de cautela quanto a esse caminho. Na origem, houve quem propusesse - até certo ponto na mesma direção do que aqui se sugere - que ele atuasse mediante interações com os outros ramos do direito, para a compreensão do sistema jurídico como um todo, não se limitando a um ramo específico (BERCOVICI, 2013, p. 259). Essa caminho, como sabemos, não prosperou, tendo vingado, após longa polêmica, o fechamento disciplinar do Direito Econômico.

Assim, dentre os caminhos possíveis para o Direito, um deles seria se integrar ao novo "campo de públicas", o que tende a ocorrer em cursos novos, organizados em bases multidisciplinares ${ }^{6}$, em geral sob a hegemonia da Ciência Política. Essa

\footnotetext{
${ }^{6}$ É o caso, em São Paulo, dos cursos de Gestão de Políticas Públicas da Escola de Artes e Ciências da USP (EACH) e da Universidade Federal do ABC (UFABC), bem como o curso de Direito da Universidade Federal de São Paulo (UNIFESP), entre outros.
} 
linha tem como risco o enfraquecimento do referencial próprio do Direito no processo de integração.

Uma outra possibilidade é a propriamente multidisciplinar. O reconhecimento dessa qualidade das políticas públicas implica que o conhecimento produzido sobre elas seja resultado de "diálogos entre os enquadramentos conceituais e as teorias que cada campo disciplinar mobilizou" (MARQUES; FARIA, 2013, p. 09). Esses diálogos são condição para a interdisciplinaridade, quando então se ultrapassam as fronteiras de cada disciplina?

Mas a multidisciplinariedade é complexa e a inserção do Direito nesse cenário faz redobrar essa complexidade, a começar pela reserva das demais áreas em relação às práticas e linguagem jurídicas ${ }^{8}$. Para o Direito, isso implica a definição dos termos de um diálogo estruturado com as demais disciplinas, sem perder suas características próprias.

${ }^{7}$ Adota-se aqui termo multidisciplinar, na linha de Marques e Faria (2013), referindo-se à convivência
entre campos disciplinares que dialogam, mantendo seus limites originais. Com base em Piaget,
os autores diferenciam essa relação da interdisciplinar, na qual "cria-se uma interação entre duas
ou mais disciplinas em uma mesma investigação, havendo intercâmbio e integração, sendo os
conceitos e teorias utilizados repensados conjuntamente e as metodologias compartilhadas pelas
várias disciplinas. (...) Na transdisciplinariedade, vista como etapa superior da integração entre
as disciplinas, a cooperação entre as várias áreas é tamanha que se torna difícil separá-las, o que
poderia desembocar na criação de uma nova macrodisciplina." (p. 15-16, nota 3).
${ }^{8}$ No Congresso de 2019 da IPPA (International Public Policy Association), instituição que congrega
pesquisadores do mundo inteiro sobre as políticas públicas, dentre quase 200 grupos de trabalho
não havia um sequer que tratasse do tema pelo ângulo jurídico. No anúncio da recém-criada
revista da Associação, havia um convite amplo, para colaborações de todas as correntes. "The
journal hosts contributions on theories of the policy process, empirical tests of models, agenda-
setting, decisions, policy instruments policy types, policy change, policy implementation,
evaluation \& appraisal, and a host of other social-scientific issues revolving around public policy.
IRPP publishes both comparative studies and single case studies. Methodologically, it is
completely open to individual methods (such as experiments, statistics, qualitative and
interpretive methods) as well as to mixed-methods contributions. The IRPP does not discriminate
against any ontological presupposition. An important aim of the journal is to publish research that
has high translation value - by this, we mean policy research that makes a broad range of findings
available to policy-makers, civil society organizations, pressure groups and citizens concerned
about policy issues. The journal does not accept political/policy commentary, explanations of legislation
and courts andinions."
(hecisions, (http://www.ippapublicpolicy.org/announcement/international-review-of-public-policy-irppsubmit-an-article/224). A ressalva, em destaque no original, coloca no mesmo nível de produção indigna de crédito acadêmico as opiniões pessoais e políticas, as análises de legislação e decisões judiciais. Nos foros multidisciplinares no Brasil, embora com mais cortesia, a abertura para o direito não é muito distinta. 
A finalidade deste ensaio é especular sobre as bases metodológicas da abordagem Direito e Políticas Públicas (DPP) ${ }^{9}$, bem como sobre suas aplicações, isto é, suas aptidões analíticas, de modo que o Direito possa dialogar com outras disciplinas ou mundos profissionais contribuindo para a compreensão de problemas públicos amplos e complexos, em sua dimensão jurídica.

\section{O MÉTODO COMO CONDIÇÃO PARA A PRODUÇÃO COLETIVA DO CONHECIMENTO}

Um método é uma necessidade evolutiva para o desenvolvimento de um campo de conhecimento. Ele é o caminho pelo qual se dá o conhecimento, o que implica consciência sobre o sujeito e o objeto do processo. Indagamo-nos: para que serve a abordagem DPP? Quais os ganhos analíticos que ela proporciona em relação ao descrito à teoria e prática do Direito estabelecido?

A complexidade inerente ao processo de policymaking, com múltiplos atores (grupos de interesse, agências governamentais etc.), ciclos políticos longos e a vasta quantidade de variáveis nos programas governamentais demanda necessárias estratégias de simplificação (SABATIER, 2007). Essas passam pela construção de uma conceptualização, a partir da intuição e da experiência (MACHADO, 2017), que as represente, na forma de conceitos e categorias abstratos, organizados numa estrutura de conhecimento, que será utilizada em processos cognitivos de comparação e na própria operação dos programas de ação governamental. $\mathrm{O}$ pressuposto desse processo, baseado no método científico, é compreender as relações críticas que sintetizam a complexidade de determinado fenômeno (ex. Darwin e a seleção natural) (SABATIER, 2007).

A validade da aplicação do método científico às políticas públicas, segundo Sabatier, estaria sujeita a algumas condições: i) as proposições devem ser tão gerais quanto possível e devem se dirigir explicitamente a incertezas relevantes; ii) os conceitos e proposições devem ser claramente definidos e logicamente consistentes, podendo ser testados por hipóteses empiricamente falseáveis; e iii) a coleta e análise de dados deve ser apresentada publicamente, de modo que possa ser replicada. Em resumo, a diferença entre o senso comum e o método científico é que a ciência é concebida para ser conscientemente orientada à procura do erro e à sua autocorreção.

Todos esses aspectos são importantes para a pesquisa jurídica na área das políticas públicas. A formação dos cursos jurídicos em regra é voltada ao desenvolvimento de capacidades argumentativas, que privilegiam a defesa de pontos de vista previamente escolhidos. Tal habilidade é uma necessidade no âmbito profissional, em que se atua com base na defesa de teses, em juízo ou fora

\footnotetext{
9 Em trabalhos anteriores, foi utilizada a expressão "abordagem de Direito e Políticas Públicas" (BUCCI, 2017; BUCCI; COUTINHO, 2016), que aqui se simplifica para a forma "abordagem Direito e Políticas Públicas".
} 
dele. Talvez por isso se veja com alguma frequência a confusão de certas prática de "pesquisa" em Direito, organizadas em torno da argumentação do pesquisador em defesa de valores da ordem jurídica. O trabalho, então, passa a ser a demonstração dos fundamentos daquela certeza - muitas vezes a pretexto de reafirmar a legitimidade do compromisso social do autor - acrescentando pouco ou nada sobre aquilo que se buscava conhecer. O uso do cachimbo faz a boca torta, diz o ditado. O exercício das profissões jurídicas pode embotar no acadêmico a capacidade de perguntar. Mas cabe ressalvar a recíproca: a falta de vivência do mundo real do direito às vezes pode produzir perguntas de pesquisa fantasiosas ou irrelevantes.

$\mathrm{O}$ transbordamento de práticas do mundo profissional sem mediações para o âmbito acadêmico é um problema específico do universo jurídico. A indiferenciação entre as identidades próprias e os propósitos de cada um desses dois mundos está na raiz do que se propõe aqui a enfrentar, a superação dos "recursos metodológicos escassos e frágeis" (COUTINHO, 2013, p. 182), se se pretende construir maior solidez na abordagem DPP.

“(...) dado que juristas brasileiros têm grande influência no modo como políticas públicas são moldadas, ajustadas e implementadas (na qualidade de legisladores, juízes e burocratas, respectivamente), é preciso reconhecer que são igualmente importantes as habilidades que lhes permitam conhecê-las em suas peculiaridades setoriais e meandros (...)"(COUTINHO, 2013, p. 184)

Para a construção dessa consciência metodológica na abordagem DPP, voltemos às teorias sobre políticas públicas, que, segundo SABATIER (2007), quando se estabelecem como referência, costumam observar os seguintes traços gerais:

1. Atendem aos critérios de uma teoria científica: conceitos e proposições são relativamente claros e internamente consistentes; identificam claramente direcionadores causais (causal drivers), dão margem a hipóteses falseáveis e têm escopo razoavelmente abrangente (isto é, são aplicáveis à maioria dos policy process em diversos sistemas políticos).

2. Têm desenvolvimento conceitual recente e verificação empírica e são vistas por uma quantidade significativa de estudiosos de políticas como caminho viável para compreender o processo político.

3. São teorias positivas buscando explicar boa parte do processo político; contêm alguns elementos explicitamente normativos, embora esses não sejam indispensáveis. 
4. Trabalham com os fatores que os cientistas políticos tradicionalmente consideraram importantes: valores e interesses em conflito, fluxos de informações, arranjos institucionais e variações no ambiente socioeconômico. (SABATIER, 2007, p. 08, destaquei)

A capacidade de servir de apoio para outros estudos (cf. item 2, em destaque), a partir do quadro conceitual por ela fornecido, é um dos indicadores da relevância de uma teoria. Sob esse aspecto, é interessante a fundamentação metodológica de Elinor Ostrom na utilização da Análise Institucional e Desenvolvimento, baseada na teoria da escolha racional, que Sabatier destacava ser a única autora no campo cuja teoria é largamente utilizada fora dos Estados Unidos. A relação entre as formulações conceituais e a base empírica do método de Ostrom está descrita em nota introdutória a $\mathrm{O}$ governo dos bens comuns, que sintetiza o empreendimento acadêmico de uma vida, cuja importância foi reconhecida pela atribuição do Prêmio Nobel de Economia de 2009, pela primeira vez a uma mulher. O que notabiliza esse trabalho é ter contrariado o senso comum, demonstrando que a administração de recursos comuns não leva necessariamente à sua destruição, mas, ao contrário, a autogestão e a auto-organização são possíveis e empiricamente demonstráveis em arranjos institucionais com certas características, o que reforça a credibilidade de abordagens ecológicas sobre problemas contemporâneos (OSTROM, 2011).

Essa demonstração foi feita a partir de estudos sobre a ação coletiva voltados à gestão de recursos hídricos na Califórnia, que nos anos 1960 estavam ameaçados pelo risco de invasão do Oceano Pacífico, o que causaria grave impacto ambiental. A análise de numerosos estudos comparativos de várias bacias subterrâneas, que tomaram as décadas seguintes, permitiu encontrar os fatores que explicavam com relativa segurança a existência de arranjos institucionais bem sucedidos na defesa do patrimônio de uso comum. Esse trabalho empírico mais amplo foi realizado no Painel sobre o manejo de recursos de propriedade comum, promovido pela Academia Nacional de Ciências dos EUA, em 1985, que seguia um marco orientativo comum aos seus vários integrantes - as categorias de análise a serem consideradas nos vários estudos haviam sido previamente pactuadas. A partir daí, realizou-se a coleta e catalogação de uma infinidade de estudos que havia à época, publicados de maneira esparsa, em revistas às vezes desconhecidas. Ostrom observou que "havia se acumulado grande quantidade de conhecimento sumamente especializado, sem que se fizesse uma síntese ou aplicação a problemas de políticas públicas" (OSTROM, 2011, p. 22).

O trabalho que se seguiu, a cargo de uma rede de pesquisadores financiados pela National Science Foundation, foi desenvolver uma codificação estruturada, com base em critérios definidos, extraídos das informações apresentadas nas pesquisas 
de campo $^{10}$. Essa codificação, em si um trabalho teórico, aplicada aos estudos existentes, permitiu a construção de um repositório de informações, em que os elementos qualitativos de cada estudo foram traduzidas em dados suscetíveis de análise quantitativa. Posteriormente, o método de análise institucional foi utilizado como marco organizador para o desenho dessas formas, cruzando as hipóteses enunciadas pelos pesquisadores de campo com a medição dos conceitos e o estabelecimento de relações com as formas de codificação em desenvolvimento. Ao longo do processo, vários ensaios foram escritos, "com a finalidade de elucidar uma teoria que nos ajudaria a compreender os padrões que começávamos a vislumbrar ao ler esses materiais" (OSTROM, 2011, p. 23). Há uma relação entre pesquisa empírica e suas bases conceituais e o entendimento da alimentação recíproca de ambas resulta na compreensão mais profunda dos fenômenos. "O conhecimento se incrementa através do contínuo ir e vir da observação empírica e esforços sérios de formulação teórica" (OSTROM, 2011, p. 23). Com informação similar sobre muitos cenários se começa a adquirir a base empírica necessária a melhorar a compreensão teórica sobre funcionamento das instituições e como os indivíduos as modificam.

A progressiva estruturação do conhecimento, com base nessa interação entre teoria e empiria - que expressa a importante contribuição metodológica de Ostrom (SABATIER, 2007, p. 09) -, resulta em vários tipos de representações possíveis, com diferentes especificidades e escopos:

1. Quadro conceitual (conceptual framework)- conjunto de variáveis e as relações entre elas, que presumivelmente são responsáveis por um conjunto de fenômenos; fornece desde um modesto quadro de variáveis até um paradigma. Não precisa indicar direções entre as variáveis, embora quadros mais desenvolvidos especifiquem hipóteses.

2. Teoria- conjunto de relações mais denso e com maior coerência lógica. Apresenta valores para as variáveis e geralmente especifica como as relações variam de acordo com os valores das variáveis críticas. O mesmo quadro conceitual pode ser utilizado por diversas teorias.

3. Modelo- representação de uma situação específica; usualmente de escopo menos abrangente e mais preciso (idealmente matemático). (OSTROM, 2007)

Na Ciência Política ou no subcampo da Análise de Políticas Públicas, há grande número de quadros conceituais, teorias ou modelos que se tornaram bastante conhecidos para uma aproximação em relação ao problema da decisão

\footnotetext{
${ }^{10}$ Os critérios eram os seguintes: i. estrutura do sistema de recursos; ii. atributos e comportamento de quem se apropria dos recursos; iii. as regras usadas por essas pessoas; iv. os resultados que decorriam do seu comportamento.
} 
governamental. Os manuais costumar apontar o ciclo de políticas públicas, também chamado de a "heurística das fases"; o incrementalismo, de Charles Lindblom; a racionalidade limitada, de Herbert Simon; os Múltiplos Fluxos, de John Kingdon; a tipologia de políticas públicas e as arenas decisórias, de Lowi, o Modelo da Lata de Lixo, de Cohen, March e Olsen; entre outros (SABATIER, 2007; MARQUES, 2013; SOUZA, 2007). Cada um deles, pode-se dizer, é parcialmente explicativo, na medida em que privilegia um aspecto de análise, enfatizando elementos distintos.

Conhecer esses modelos e seleções é importante para uma abordagem jurídica, uma vez que eles evidenciam o mundo que há nas políticas públicas para além do elemento jurídico. A política pública, como se sabe, não se reduz às disposições da Constituição ou da legislação que lhe proveem o suporte e a conformação jurídica. Embora, por outro lado, não dispense, em absoluto, essa dimensão, uma vez que toda política pública se assenta sobre elementos jurídicos.

Toda política pública, pela força das coisas, se acha implicada no espaço do direito e carrega as marcas desse encontro. Os atores nunca deixam de contar o jurídico em seus cálculos estratégicos e além disso, as ações seguem trajetórias cujo desenho obedece também a considerações jurídicas. O direito ocupa um lugar na fábrica das políticas públicas, é um "material mobilizável".

É certo que o direito sozinho não fará as políticas públicas inteligíveis: sua verdade não se enuncia nas categorias do pensamento jurídico, mas nada que tome forma e sentido de política pública escapará ao trabalho do direito.

É necessário cruzar dois tipos de exigências complementares: combinar a constituição política do direito e a constituição jurídica das políticas públicas. (CAILLOSSE, 2000, p. 46)

É relevante, ainda, que a abordagem jurídica identifique os elementos peculiares dessa composição, não se rendendo a uma falsa interdisciplinaridade ${ }^{11}$ que consiste em trabalhar, sem maiores mediações, teorias ou pautas de pesquisa assentados em premissas que fazem sentido na visão econômica ou política, mas não necessariamente no Direito. Uma abordagem desenvolvida nesse campo requer reflexão consistente sobre quais são seus pontos de partida, sua identidade própria e seus "pontos de chegada" (COUTINHO, 2013, p. 193).

Para isso faria sentido aplicar como teste o conflito disciplinar referido por Marta Farah, verificando se aquilo que se propõe estudar pela perspectiva da abordagem DPP não pode ser compreendido e resolvido mais diretamente aplicando-se, "com um grão de sal", o direito tradicional. Isso para diferenciar de construções aparentemente originais que, sob a rubrica do Direito e Políticas

${ }^{11}$ Sobre a interdisciplinaridade em Direito e Políticas Públicas, ver artigo de Ester Rizzi e Gustavo Bambini neste dossiê. 
Públicas, na verdade expressam uma acomodação cognitiva, em que o pesquisador combina, sem maior rigor ou justificativa, elementos de concepções epistêmicas distintas, no chamado "sincretismo metodológico" (AFONSO DA SILVA, 2005). Assim se obtém uma posição ad hoc, pouco mais que uma impressão, eminentemente autoral, não uma conclusão que possa ser contraposta (e, portanto, falseada), caso os fundamentos não tenham consistência teórica ou empírica - o que está na base do método científico. $\mathrm{O}$ abrigo no guarda-chuva argumentativo, que o estudioso do Direito acredita possa dispensá-lo de demonstrar a validade de suas conclusões em outras situações sob condições semelhantes, cobra seu preço em termos de consistência dos resultados e relevância do conhecimento produzido.

O que se busca é uma base metodológica clara, sobre o qual a abordagem possa se desenvolver com maior amplitude e abrangência. Para tanto são necessários esquemas de representação e sistematização conceitual que possam ser empregados como modos de simplificação efetivos na aproximação e compreensão de políticas públicas determinadas, em sua escala real. O que faz a força do quadro conceitual, teoria ou modelo, é ser visto como esquema útil para análise de problemas complexos, segundo categorias estruturantes e uma tipologia de variações que faça sentido como esquema de simplificação, permitindo descrever e compreender uma gama de fenômenos razoavelmente diversificada. A aplicação do esquema analítico aos casos concretos, por sua vez, deve servir como instância de teste e validação do método. ${ }^{12}$

\section{AS TRANSFORMAÇÕES DO ESTADO NA TEORIA DE DIREITO E Políticas Públicas. O “Direito labirinto" COMO hipótese PARA SEU REDUZIDO ALCANCE APLICADO.}

A necessidade de método para a abordagem DPP não é uma demanda apenas local. Há autores que se aprofundaram no assunto, em âmbito internacional, sem, todavia, "fazer escola". A expressão é utilizada aqui não no sentido mais corriqueiro entre nós, como séquito de discípulos atrás de uma figura proeminente no mundo do Direito, mas no sentido de produção acadêmica de referência que, ao equacionar determinado problema, funda uma linha de pensamento ou abordagem que gera atrás de si uma corrente de estudos, como Sabatier qualifica a obra de Elinor Ostrom, acima citada.

Esse poderia ser o caso de autores como William Clune e Charles-Albert Morand, que produziram importantes contribuições e análises originais sobre a relação entre Direito e Políticas Públicas. A despeito disso, por alguma razão o

${ }^{12}$ Os artigos de Carlos Toledo, Frederico Haddad, Ighor Rafael de Jorge, Marcelo Chilvarquer, Rafael Taranto Malheiros e Sérgio Valente, neste dossiê, consistem em estudos aplicados sobre temas específicos, que ao utilizar conscientemente roteiros metodológicos afeitos à abordagem DPP (cf. item 5.1, abaixo), além de produzir compreensão mais abrangente sobre os problemas examinados, validam a metodologia. No mesmo sentido, os artigos de Clarice Seixas Duarte e Patrícia Ulson Werner. 
alcance de sua obra permaneceu limitado e até onde se pode pesquisar, teve poucos seguidores.

William Clune $(1983 ; 1993 ;$ 2001), professor da Universidade de Wisconsin, tem diversos artigos dedicados ao tema ${ }^{13}$. Neles, procura explicar os efeitos do welfare state americano, em construção desde os anos 1930, e suas influências sobre o mundo jurídico, em especial quanto à presença crescente de argumentos de política.

Desde o advento do realismo jurídico, o discurso do direito passou a se basear largamente em argumentos de política, se referindo a algo ao mesmo tempo poderoso e periférico em relação ao sentido do texto. Governos aprovam leis e as usam para realizar políticas [...] tendo algo a ver com o bem estar material para grande número de pessoas. Política pública, nesse sentido, é a estrutura para as economias de mercado e os welfare state modernos que regulam a produção econômica, o consumo e as trocas. (CLUNE, 1993, p. 02)

Os "estudos interdisciplinares", compartimento dos cursos jurídicos em que se enquadrava a Law and Public Policy, têm origem no reformismo social em marcha nos Estados Unidos desde a década de 1930 e mais intensamente depois da guerra ${ }^{14}$, segundo Duncan Kennedy, com quem Clune dialoga (CLUNE, 1993; 2011). Na formação americana, esse componente curricular surgiu como parte da onda de expansão do Direito Público ${ }^{15}$ e outras inovações pedagógicas, como a criação das

\footnotetext{
${ }^{13}$ Ver artigo de Matheus Silveira de Souza e Maria Paula Dallari Bucci, neste dossiê, que registra o resultado de pesquisa na bibliografia internacional sobre a produção específica sobre Direito e Políticas Públicas.

14 "Law in action versus law in books era uma coisa e a outra eram estudos de viabilidade ou de implementação. Law-and-x significava que depois de demonstrar que o mundo real não era igual ao pintado pela doutrina, você fazia um estudo para mostrar que um programa legislativo específico deveria ser aprovado. Era um apelo à ciência social para justificar um programa público de reforma legislativa." (KENNEDY, p. 5). Law-and-x, segundo o mesmo autor, é uma referência aos estudos de Law and Economics, Law and Development e outras áreas de estudos interdisciplinares surgidos nos anos 1960, na mesmo impulso de reformismo social e jurídico.

${ }^{15}$ A expressão Direito Público, para o autor, tem diferenças em relação ao sentido que comumente lhe atribuímos: "Não havia um corpo significativo de direito administrativo em nenhum país de língua inglesa até a criação do welfare state, com seus programas de assistência pública e suas múltiplas formas de intervenção na vida econômica. [...] Se tomarmos o direito administrativo, direito do trabalho, direito antitruste, direito dos serviços públicos [public utilities] e da tributação em conjunto, esses corpos jurídicos encarnam o objetivo de transformação social por meio de programas legislativos." (KENNEDY, p. 3-4) Em outra passagem o autor acrescenta os direitos ambiental, municipal, do consumidor e da saúde (p. 8).
} 
clínicas jurídicas ${ }^{16}$, expedientes de uma nova cultura jurídica que se formava para fazer frente ao direito liberal do laissez faire que predominara nos EUA no séc. XIX e seguia estruturando o cerne do ensino jurídico no séc. XX, baseada nos conceitos de propriedade, contratos e responsabilidade civil (torts). Mais tarde, para Kennedy, essa linha perderia seu caráter progressista, passando a se orientar por um reformismo moderado ad hoc, utilitarista e desintegrado. E partir daí, a policy analysis passaria a entrar em todos os campos, banalizada: "Não há regra que não possa ser legitimada pela referência a um conjunto de políticas sociais." (KENNEDY, 1983, p. 08). Na verdade, a crítica de Kennedy era mais ampla, referindo-se a uma onda conservadora que teria esvaziado, no ensino jurídico, as várias frentes do progressismo.

Clune não compartilha o ceticismo de Kennedy. Ele entende que o núcleo central da formação jurídica, realmente mais conservador, passa a interagir dinamicamente com a "periferia" reformista, à semelhança do que ocorre com o próprio Estado.

O direito é uma pequena fortaleza que oferece uma perspectiva restrita e artificial do mundo exterior, pelas estreitas vigias do método jurídico e dos procedimentos legais. Mas as portas estão abertas e o forte se enche de diferentes estrangeiros a cada dia. (CLUNE, 2011, p. 192)

A Law and Public Policy é filha do instrumentalismo, da engenharia social dos welfare states, mas tem influências duradouras sobre as instituições jurídicas. Essas influências se manifestam das seguintes formas:

1. Estruturação do direito em torno de problemas de desempenho econômico- $\mathrm{O}$ direito tende a ser organizado em função dos grandes problemas das modernas economias: regulação da economia, transferências de renda, saúde, educação e formação profissional, emprego, meio ambiente etc.

2. Cooperação social e produto social líquido positivo- Os esforços para levar os conflitos sociais numa direção social positiva são o maior enigma do welfare state moderno. Clune não nega o conflito [o que seria típico do pensamento conservador], mas realça a lógica das políticas públicas, em que a importância da formação de consensos muda os

\footnotetext{
${ }^{16}$ As clínicas jurídicas eram serviços de atendimento à população carente, criados para proporcionar "aos estudantes de classe média experiências de contato direto com a vida real dos pobres" (KENNEDY, p.7).
} 
procedimentos das disputas sociais, não se compatibilizando com a polarização política extrema.

3. Persistência das estruturas legais ao longo do tempo- A estrutura regulatória [neste caso tomada como sinônima de políticas públicas] é complexa e leva tempo para se desenvolver. A existência dessas estruturas facilita o investimento social.

4. Organização em torno de grandes agregados sociais- A organização econômica capitalista coloca grandes quantidades de pessoas em situações similares ["massificação"], o que dá margem a considerar economias de escala.

5. Capacidade de planejamento e adaptação- As estruturas jurídicas que persistem devem ter capacidade de adaptação e mudança.

6. Direção central através de delegação e descentralização- $O$ problema de como dirigir atores autônomos sem destruir a sua autonomia. O monitoramento com base em critérios selecionados exige mecanismos poderosos de coleta de dados e simplificação da informação.

7. Hibridismo [commingling] de autoridade pública e privadaAinda que se afirme que direito é essencialmente um ato de autoridade pública, as demandas das políticas públicas levam o direito a uma relação de cooperação do Estado com o setor privado. Isso se dá por meio de um complexo processo de sinalização e incentivos. O direito nas áreas de políticas públicas é caracterizado por muita comunicação e negociação.

8. Modificação do acesso político, à luz das demandas por desempenho- As políticas públicas exercem pressão contínua sobre a organização da política: criação de agências especializadas, correção de desbalanceamentos políticos, agregações de interesses mais ordenadas e coerentes, com exemplos na "grande arquitetura da representação" em welfare states (como os sindicatos e partidos políticos, por exemplo), e em áreas específicas de policy making. (CLUNE, 1993, p. 09-13)

As áreas principais de interesse para a abordagem interdisciplinar, segundo o autor, focam problemas relativamente novos na segunda metade do século XX, mas que ainda hoje, por sua complexidade, demandam um tratamento mais abrangente que o proporcionado pelo direito tradicional, tais como meio ambiente, ciência e tecnologia etc. (CLUNE, 1993).

Clune observa uma mudança profunda produzida no paradigma jurídico, confrontando-se o formalismo e a doutrina jurídica tradicionais com o 
consequencialismo e o instrumentalismo ${ }^{17}$ do novo modelo. Tensão semelhante, diga-se, está em grande evidência no direito brasileiro desde a Constituição de 1988, igualmente fundada em uma "demanda de rematerialização do direito" como a observada por Clune em seu texto, que acirra o pragmatismo social e provoca ceticismo sobre debates jurídicos. Qual seria o papel da interpretação jurídica onde o desempenho social, e não o significado, é a base da policy analysis? (CLUNE, 1993, p. 19-22)

Mas, adverte o autor, a falha em entregar resultados - que às vezes decorre da desorganização política - pode colocar em tensão a legitimação jurídica. Quando se adota a retórica das consequências sociais sem atenção às realidades empíricas, geralmente não há ganho em efetividade. Diante do utilitarismo passageiro o direito se arrisca ao colapso, mantendo funções meramente simbólicas. Além disso, se há casos de falso consequencialismo existem também os falsos raciocínios jurídico-formais, o que termina por minar a lógica de responsividade social que deveria estar na base das políticas públicas. Isso provocaria a perda de independência do Direito como fonte de significado, afetando a conformação de direitos e o desenvolvimento jurídico subsequente. (CLUNE, 1993, p. 19-22)

Por outro lado, Clune observa que as políticas públicas foram introduzidas numa era de estruturas grandes e relativamente estáveis, que disciplinaram muitas transações durante $\operatorname{anos}^{18}$. O direito preservou sua integridade conceitual e consequencial em áreas em que as consequências sociais são mais observáveis, em que o sentido dos programas pode ser apreendido no desenho geral das leis e em sua história legislativa. Isso confirma que a relativa autonomia do direito se manifesta na institucionalização das políticas (CLUNE, 1993, p. 19-22).

Abram-se parênteses para dizer que a persistência das estruturas legais ao longo do tempo - que poderia ser exemplificada, no caso do Brasil, com a estruturação constitucional do Sistema Único de Saúde e da assistência social, por exemplo - tem sido um dilema para a teoria jurídica das políticas públicas, uma vez que nem sempre é possível compatibilizar tais sistemas (de vocação permanente, "políticas de Estado") com a noção de programa de ação governamental que tem sido adotada como delimitador da política pública em relação ao entorno jurídicoinstitucional. Como já se disse, geralmente uma política nasce "de governo" e se transforma em "de Estado", à medida em que assume uma institucionalização mais completa, passando a depender menos das forças políticas que patrocinaram o seu nascimento (BUCCI, 2013).

Charles Albert Morand, professor da Universidade de Genebra, na Suíça, publicou, em 1999, livro pioneiro na área jurídica, sua derradeira obra, Le Droit Neo-

${ }_{17}$ A expressão na redação original é social engineering, que tomei a liberdade de traduzir como instrumentalismo, mais próxima de nosso contexto.

$18 \mathrm{O}$ autor cita como exemplos o Equal Employment Act, que autorizava o governo a processar empresas que discriminassem para a oferta de emprego com base em raça e outros fatores, e a regulamentação do transporte escolar. 
Moderne des Politiques Publiques (O Direito Neo-Moderno das Políticas Públicas, sem tradução em português). Nesse trabalho, o autor examina o efeito das políticas públicas sobre o Estado, na busca de compreender as transformações dos anos 1990, quando a globalização e a financeirização do capitalismo mundial, de um lado, e os novos arranjos jurídico-institucionais precipitados pela União Europeia, de outro, proporcionaram uma alteração profunda no panorama jurídico global. O que há de mais interessante nesse trabalho é a clara vinculação da temática do Estado ao surgimento e expansão da figura das políticas públicas, expediente cognitivo e de ação importado, em grande medida, da experiência norte-americana para o contexto europeu.

$\mathrm{O}$ autor se baseia numa tipologia que relaciona os tipos de sociedade, Estado e a forma jurídica dominante: a) sociedade pré-moderna/Estado repressivo/direito repressivo; b) sociedade moderna/Estado liberal/direito restitutivo; c) sociedade complexa/Estado intervencionista/direito finalístico; d) sociedade hipercomplexa/Estado dirigente/ direito reflexivo (MORAND, 1999). A partir dessa, desdobra-a em três modalidades de Estado, propulsivo, reflexivo e indutor, às quais correspondem, respectivamente, os programas finalísticos, as negociações e as formas de indução. $\mathrm{O}$ qualificativo de neo-moderno se justificaria pelo efeito híbrido da colagem dessas inovações trazidas pelas políticas públicas à base jurídica do Estado-liberal, o "direito moderno".

$\mathrm{O}$ advento do Estado-providência, o Estado dos serviços públicos, teria principiado o movimento de suavização da coerção, com a mistura do direito público e privado e a substituição de exigências de regularidade por normas de desempenho. Ali teria surgido uma normatividade indutora, com a instrumentalização do jurídico pela política e pela economia. Além disso, teria se ampliado o uso de figuras equivalentes às do mercado, num movimento de privatização das modalidades de ação pública, impondo a combinação de direito público e privado. Na prática jurídica, a tendência ao sopesamento de interesses teria significado o emprego crescente de meios convencionais, em detrimento dos unilaterais (MORAND, 1999).

Com isso, teria sido retirada do direito a transcendência, mesmo simbólica, e ele teria deixado de ser "o portador privilegiado de valores e de verdades universais para se tornar "meio ordinário da ação do Estado, ao lado do dinheiro e da informação'" (CAILLOSSE, 1999, p. 513-514). Haveria um “derretimento" do caráter unificador do direito, fenômeno, de resto, mais geral no Estado social (EWALD, 1988).

Mas isso não desperta em Morand (1999, p. 189) a nostalgia da ordem jurídica liberal e sua previsibilidade. Ao contrário, “o direito das políticas públicas não representa uma degradação do modelo de direito moderno, mas a irrupção de uma nova figura da racionalidade jurídica na qual o direito está inteiramente fundado no imperativo da eficácia". O problema é que "as ferramentas mentais cujo uso foi 
perpetuado pelos juristas não foram pensadas para apreender a realidade complexa e aleatória das políticas públicas." (CAILLOSSE, 1999, p. 514).

Morand procura enfrentar essa limitação elencando numa estrutura sistemática a variedade de manifestações jurídicas dessa realidade complexa, tomando como referência a tipologia dos Estados e seu direito característico. As formas jurídicas associadas ao Estado indutor, ao Estado-reflexivo e ao Estado-propulsivo comporiam o acervo do direito das políticas públicas.

Para enfrentar o problema essencial da conciliação entre autonomia e direção que aparece em Clune (1993) como a tensão entre direção centralizada e execução descentralizada -, Morand (1999, p. 132) observa, na linha da autopoiese, que ao invés de intervir do exterior impondo autoritariamente suas soluções, o Estado, por meio de programas relacionais, busca criar estruturas interiores reflexivas ao sistema que ele quer orientar.

Os meios de ação passam a envolver a contratualização, tanto na formação, como na implementação e na aplicação do direito. No processo de formação da legislação, ela reforça o sentido corporativo, em que a necessidade de acordo com os grupos envolvidos funciona como sanção invertida, isto é, como uma ameaça pesando sobre o governo e o parlamento. No nível regulamentar, o governo e os grupos privados podem aparecer como co-autores de um ato, num fenômeno de conormatividade. Isso não se confunde com o pluralismo normativo, em que várias ordens normativas convivem com a estatal (ex. nova lex mercatoria, lex informatica, lex sportiva internationalis) e novas formas de reenvio normativo, tais como a autorregulação dirigida (MORAND, 1999). A valorização do processo de produção das normas dá margem ao crescimento da Teoria da Legislação ou Legística, que tem em Alexander Flückiger ${ }^{19}$ um continuador da obra de Morand.

[...] num contexto cada vez mais mergulhado em normas sem coerção [droit souple/soft law] que desafiam o legislador: uma legística que deverá se inscrever no coração do Estado de direito e da democracia numa governança multiníveis na era do direito global. Os legisladores serão obrigados a desenvolver, dentro das políticas públicas que eles instauram, estratégias de impacto necessariamente menos diretas, mais suaves [souples], menos espetaculares para tentar se impor democraticamente. A força da lei estará numa reapropriação estratégica de todos os instrumentos de ação à sua disposição, jurídicos e não jurídicos, públicos ou privados, unilaterais ou cooperativos, normativos ou materiais, fortes ou fracos, coercitivos ou não: a legislação se torna o maestro da regulação. Uma legística que

${ }_{19}$ Professor da Faculdade de Direito Universidade de Genebra e membro do Centre d'étude, de technique et d'évaluation législatives (CETEL). Agradeço a Ighor Rafael de Jorge a indicação. 
ultrapassa o simples texto, voltada à substância da norma para assegurar um impacto tão justo quanto eficaz. (FLUECKIGER, 2019, p. X)

Essa breve resenha demonstra o ganho proporcionado pelo inventário e entendimento dessas inovações jurídicas, se se pretende uma compreensão aprofundada do que caracteriza a nova racionalidade jurídica setorizada das políticas públicas. Aí pode estar uma chave metodológica para o entendimento das estruturas e da dinâmica do "Estado neo-moderno", em que, segundo Morand, as diferentes formas estatais e suas expressões jurídicas, a propulsão, a negociação e a indução, não se sucedem, mas coexistem, como camadas geológicas comprimidas e mescladas.

Como vimos, a despeito da riqueza analítica - e talvez por causa dela e de sua complexidade - a utilização dessas percepções em termos de reflexão sistemática sobre o direito e suas relações com a política, segundo um quadro teórico mais estabelecido, ainda carece de desenvolvimento. No plano metodológico, o "direito labirinto à espera de uma teoria" (AUER et al., 2001) parece inspirar mais receio do que sedução acadêmica, hipótese que explicaria as descontinuidades na pesquisa em Direito e Políticas Públicas.

Mas há uma razão de fundo apontando outro tipo de desafio para o desenvolvimento da abordagem DPP. Trata-se da longa crise do Estado contemporâneo ${ }^{20}$ (RIBEIRO; BUCCI, 2018), em face dos abalos iniciados nos anos 1970 seguidos pelas transformações analisadas por Clune e Morand, posteriormente acentuadas com a intensificação avassaladora das tecnologias de informação e comunicação em todos os planos da vida social, associada ao fortalecimento da economia de serviços e o declínio da economia industrial, afetando não apenas as relações de trabalho, mas as dimensões política, econômica, urbana e ambiental das relações humanas.

As políticas públicas emergem como temática, em diversas áreas acadêmicas, com diferentes denominações (Análise de Políticas Públicas, Gestão de Políticas Públicas, Administração Pública, "campo de públicas" etc.), como resposta a essa crise, como demonstram reflexões conceituais e metodológicas similares a que aqui se empreende (MARQUES; FARIA, 2013; FREY, 2000; FARRANHA; SOARES; MIRANDA, 2019). Busca-se entender as novas configurações do Estado, seus papeis e modos de ação, não mais redutíveis à estrutura monolítica tradicional que ocupava o centro único da esfera política e atuava como fonte exclusiva do Direito. Documentar, analisar e compreender de forma sistemática esses novos padrões de ação estatal, em sua dimensão jurídica, constitui razão de ser da abordagem Direito e Políticas Públicas. Seu objeto é a ação governamental coordenada e em escala ampla, para atuar sobre problemas complexos, em estratégias juridicamente informadas, para estender as conquistas civilizatórias a todas as pessoas.

${ }^{20}$ Ver artigo de Ivan Ribeiro neste dossiê. 


\section{ESTADO, POLÍTICA E POLÍTICAS PÚBLICAS}

No Brasil, a área de estudos de políticas públicas nasce com a transição para a democracia, no início dos anos 1980. Com a Constituição de 1988, impõe-se a reconstrução do Estado brasileiro e suas relações com a sociedade, no período pósautoritário; "buscava-se entender o sentido, as possibilidades e obstáculos às iniciativas de mudança, inscritas na nova Constituição ou simplesmente resultantes da decisão dos governos." (ALMEIDA, 2007, p. 09). Isso implicava aproximação com a agenda política, e pesquisa aplicada para entender as reformas e a distribuição de responsabilidades e capacidades entre as esferas de governo.

O tema da Constituição social é propício a explicitar diferenças de visão entre a área jurídica e as demais ciências sociais. Para o mundo do direito, as disposições constitucionais são mandatórias ao instituir o Estado social; trata-se de uma ordem deontológica e a "força normativa da Constituição" deveria bastar para implementá-lo, legitimando o Estado a atuar sobre a economia e a política.

A Constituição do Estado social, ao incorporar em sua esfera outros direitos, além dos da primeira geração ou dimensão, entrou a exibir perfil de objetividade, concretude e materialidade normativa que só se pode compreender, explicar e interpretar à luz de uma concepção de sistema e valor; portanto, como ordenamento de eficácia jurídica vinculada principalmente a elementos materiais de conteúdo. (BONAVIDES, 2009, p. 38)

Já no universo dos economistas e cientistas políticos, o tema é mais complexo. $\mathrm{O}$ welfare state floresce nas economias centrais com o capitalismo do século XX, no processo de industrialização que conta, além do Estado prestador de serviços públicos, com o movimento sindical e partidos políticos de esquerda (ESPINGANDERSEN, 1991). Diferentes combinações entre Estado, mercado e família explicam variações no tempo e espaço, numa tipologia em que se distinguem as experiências liberais (EUA, Reino Unido, Austrália, Canadá e Nova Zelândia) das conservadoras (Alemanha, Áustria, França, Holanda e Bélgica) e das propriamente social-democratas (Dinamarca, Noruega, Suécia e Finlândia) (ESPINGANDERSEN, 1991; KERSTENETZKY; GUEDES, 2018). E é com base no reconhecimento dessa condição histórica que posteriormente se entende possível adotar esse qualificativo fora das economias centrais, em que não havia aquelas mesmas condições, nos "países retardatários" da América Latina, Ásia e na periferia europeia, à medida em que se expandem as políticas de proteção social e ações de desenvolvimento (KERSTENETZKY; GUEDES, 2018; DRAIBE, 2007).

Como país retardatário, o Brasil pactuou na Constituição de 1988 a reforma do sistema herdado do autoritarismo, em que a proteção social exclusiva aos formalmente empregados consubstanciava verdadeiro privilégio social, a 
"cidadania regulada" de Wanderley Guilherme dos Santos ${ }^{21}$, insuficiente para as demandas da população que emergiam no novo contexto democrático (ARRETCHE, 2018). Desafio adicional era materializar a Constituição social ao tempo em que suas fontes de inspiração nos Estados desenvolvidos entravam em declínio, com a guinada para a financeirização desregulada que a partir daí passou a tensionar o espaço político e jurídico dos Estados nacionais.

Para o direito brasileiro o momento é marcante, pois no final da década de 1990 a onda de privatizações deságua no primeiro grande ciclo de emendas constitucionais. No plano econômico, foi período de ajuste fiscal, restrições à intervenção do Estado na economia e introdução de políticas focalizadas (SOUZA, 2007, p. 65). No âmbito da gestão pública, além da privatização de serviços públicos e criação das agências reguladoras, é a época da reforma administrativa, que terminará por constitucionalizar como princípio a eficiência administrativa.

Nesse cenário, para os críticos, as políticas públicas seriam parte de um "Estado neoliberal, pautado e condicionado pelo mercado, ou seja, a economia de mercado determina as decisões políticas e jurídicas, relativizando a autoridade governamental" (BERCOVICI, 2004, p. 177). A reforma de grande parte da Constituição econômica teria estendido essa lógica à sociedade, com o repasse de tarefas ao mercado e o esvaziamento da política pelo direito. Em resumo, ao pretender aproximação técnica para problemas essencialmente políticos, isto é, condicionados pelo poder, as políticas públicas constituiriam formas despolitizadas de atuação do Estado.

Haveria, portanto, duas leituras em tensão. Uma delas entende as políticas públicas como desdobramentos da concepção de Estado social contida na dimensão progressista da Constituição de 1988; elas seriam "o braço executivo de direitos expressos na Constituição" (KERSTENETZKY, 2014, p. 02), filhas do instrumentalismo próprio da Constituição dirigente. As políticas públicas estariam subjacentes à ideologia democrática e inclusiva da CF 88, ainda que esse caráter não fosse hegemônico - e talvez exatamente por causa disso, ao contrário do que ocorreu com seu modelo, a Constituição portuguesa de 1976, produto da vitória de partidos à esquerda na Revolução dos Cravos. Esse é o sentido que tem sido adotado pela abordagem DPP; as políticas públicas são necessárias como

${ }^{21} \mathrm{O}$ conceito de cidadania regulada refere-se ao acesso a direitos no período varguista limitado àqueles que tinham acesso a serviços públicos de previdência e habitação, por exemplo, ligados às corporações profissionais de trabalhadores urbanos. "Por cidadania regulada entendo o conceito de cidadania cujas raízes encontram-se, não em um código de valores políticos, mas em um sistema de estratificação ocupacional, e que, ademais, tal sistema de estratificação ocupacional é definido por norma legal. [...] A extensão da cidadania se faz, pois, via regulamentação de novas profissões e/ou ocupações em primeiro lugar, e mediante ampliação do escopo dos direitos associados a estas profissões, antes que por expansão dos valores inerentes ao conceito de membro da comunidade." (SANTOS, p. 75) 
expedientes de coordenação estratégica da ação governamental, em seus vários focos de competência e decisão (União, Estados, Municípios, entes privados), sem os quais seria impossível materializar os direitos fundamentais. Dito de outro modo, seu propósito é concretizar "a constituição dirigente das políticas públicas e dos direitos sociais" (BERCOVICI; MASSONETTO, 2006, p. 19).

Mas merece ser investigada a crítica sobre a despolitização das políticas públicas, segundo a qual, sendo elas, por definição, programas de ação governamental tópicos e setorizados, não poderiam desempenhar as tarefas que incumbem ao Estado, de transformação das estruturas que produzem o subdesenvolvimento. Segundo a concepção desenvolvimentista, a "conclusão do projeto de formação nacional" depende de escolhas políticas, sendo necessária não apenas a "presença ativa e coordenadora do Estado nacional", mas a "ruptura com o sistema, internamente e com o exterior" (BERCOVICI, 2004, p. 179). Nada disso se confunde com mera modernização.

O desenvolvimento só pode ocorrer com a transformação das estruturas sociais, o que faz com que o Estado desenvolvimentista precise ser um Estado mais capacitado e estruturado que o Estado Social tradicional. E não é só o fato de não termos tido, no Brasil, um Estado de Bem-Estar Social que nos impede de construir um Estado que possa superar a barreira do subdesenvolvimento. (BERCOVICI, 2004, p. 180)

Um dos problemas dessa visão é ser essencialmente prescritiva, isto é, referir-se a um dever ser, não à existência material do Estado, em concreto. É verdade que um dos sentidos das constituições contemporâneas - nos países de desenvolvimento tardio muito mais do que naqueles em que está consolidado - é orientar os movimentos do Estado e da sociedade em direção à realização dos valores pactuados. A Constituição é “expressão também de certo grau de desenvolvimento cultural, um meio de auto-representação própria de todo um povo, espelho de sua cultura e fundamento de suas esperanças." (BERCOVICI, 2006, p. 161, citando Peter Häberle).

Mas essa aproximação totalizante, um pouco ao estilo da Teoria Geral do Estado tradicional, hoje é posta em questão, exatamente em vista da multiplicação dos sentidos que a democracia assumiu e da diversificação das formas de ação estatal. ${ }^{22}$

22“"Que sentido pôde ter e pode ter ainda hoje 'fazer teoria geral do Estado'? A expressão, banalizada, é preciso reconhecer, não inspira mais grandes obras, aquelas belas totalidades que, pelo prisma do sujeito pensante, restituem a complexidade de um objeto à sua sistematicidade - e assim o simplificam por voltar ao elementar. [...] As mutações identificadas não farão desaparecer a necessidade de sistematizar o pensamento sobre o quadro institucional da vida pública. Mas o Estado - a ideia de Estado - não constitui mais o seu coração. Ele está preso nas únicas redes que o legitimam. A teoria da democracia, por exemplo, parece ter transbordado largamente os 
Além disso como estratégia de redução de complexidade, o realce do apelo à ação implica certo prejuízo à dimensão analítica a respeito de como a ação pode se dar (OSTROM, 2007, p. 26). E isso termina por afetar também o plano da ação.

O debate mais aprofundado sobre esse tema se encontra em Theodore Lowi e sua conhecida afirmação de que "policies determine politics" (LOWI, 1972). O contexto é a descrição de como, na passagem do séc. XIX para o séc. XX, o eixo de gravidade da política dos Estados Unidos, que até então estava quase exclusivamente no Congresso (politics), especialmente em seus comitês, passa a envolver cada vez mais o governo (policies), com a assunção, por esse, de centralidade política, com maior vigor e maiores responsabilidades.

A grande contribuição do autor é uma taxonomia dos modos de ação política as funções distributiva, regulatória e redistributiva - e suas arenas, os locais onde se exerce cada uma delas (LOWI, 1964). Posteriormente, se agregará a função constitutiva, que se refere à criação de órgãos e serviços (LOWI, 1972). A premissa pluralista por trás desse esquema de categorias funcionais se contrapõe à escolha de um fator único como explicação da estrutura de poder em cada uma delas.

A política distributiva, modo de atuação prevalecente na política americana da segunda metade do séc. XIX, se caracteriza pelo clientelismo, com o atendimento atomizado de demandas, o que, exatamente pela fragmentação, ocorre sem que se estabeleça confronto direto entre os beneficiários. É o caso de benefícios tarifários, melhoramentos locais e subsídios, em que as lideranças mais influentes podem ser atendidas de forma desagregada, contemplando os eleitores de determinadas regiões. A arena prioritária desse tipo de política eram os comitês do Congresso.

No início do séc. XX cresce o número de grupos de interesse organizados nacionalmente e a capacidade desses de atuar politicamente. $\mathrm{O}$ surgimento de políticas nacionais muda o panorama do federalismo nos EUA, uma vez que, segundo a Constituição, os temas principais em matéria de políticas públicas são de competência dos estados e até o advento do New Deal, eram discutidas e realizadas nesse nível. As alternativas de políticas públicas se ampliam e surgem as políticas regulatória e redistributiva.

A política regulatória é aquela em que a decisão do governo se substitui à alocação privada dos recursos e se orienta por regras gerais, como ocorre, por exemplo, com a regulamentação trabalhista ou a organização dos sistemas de transportes. Diferentemente das anteriores, nesse caso as políticas não podem ser tratadas no nível do indivíduo ou da empresa, ainda que proporcionem benefícios ou encargos diferenciados, mas abrangem setores econômicos de forma agregada. A arena predominante tende a ser deslocada dos comitês do Congresso e das agências do governo para o próprio Congresso (LOWI, 1964).

contornos do Estado, para se transformar em democracia local, ou, ao contrário, democracia internacional, ou ainda democracia 'social'." (JOUANJAN; MAULIN, 2012). No mesmo sentido, ver GASPARDO e o artigo de Ivan Ribeiro neste dossiê. 
Finalmente, políticas redistributivas são aquelas em que alguns recebem mais em serviços do que pagam em impostos, ou em que alguém recebe um benefício sem ter contribuído para ele. É o caso típico dos programas do welfare state, como moradia ou aposentadorias e que são explicáveis com base nas classes sociais ou na oposição ricos/pobres, burguesia/proletariado. Nesses, "há um conflito estável e contínuo que só pode ser compreendido em termos de classe" (LOWI, 1964). E aqui não há como negar o peso da política na orientação do Estado e das próprias políticas públicas. Um governo conservador não produz políticas progressistas (ainda que o mundo jurídico possa creditar à Constituição essa capacidade).

A virada política dos anos 1930 nos EUA, quando as políticas regulatórias e redistributivas entraram massivamente no cenário nacional, impactou a política. Institucionaliza-se um padrão de múltiplos e distintos sistemas de políticas (distributivas, regulatórias, redistributivas e constitutivas). Quando Roosevelt expande o governo em todas as frentes, "as policies mudaram a politics, independentemente dos homens ou partidos que ocupavam a presidência ou organizavam o Congresso" (LOWI, 1972, p. 302). A marca dessa "revolução", que orientou a política americana até os anos 1970, foi a capacidade de traduzir grandes pressões em políticas públicas, ao mesmo tempo transformando-as em forças políticas significativas (LOWI, 1972, p. 302).

As políticas públicas, com sua plasticidade, provêem racionalidade às formas de coordenação e organização da ação estatal por setores e programas, em que podem se compor alianças estratégicas específicas para a formulação e sustentação de cada arranjo jurídico-institucional (BUCCI; COUTINHO, 2017). O conflito político se apresenta setorizado e é decidido em cada política pública.

Mesmo as questões estruturais, que expressam decisões políticas fundamentais, também acabam se submetendo a racionalidade similar, quando se consideram os desenhos jurídico-institucionais e a composição de arranjos sustentados em alianças políticas e sociais. Para os países de democracia recente, o desafio adicional, no campo político, é montar coalizões relativamente estáveis, para sustentar "políticas públicas capazes de impulsionar o desenvolvimento econômico e promover a inclusão social de grande parte de sua população. Respostas a esse desafio não são fáceis, nem claras ou consensuais (...) e seus processos também influenciam os resultados dos conflitos inerentes às decisões sobre política pública". Não é por outra razão que os estudos de políticas públicas consideram, além da racionalidade governamental, outros fatores como as eleições, as burocracias, os partidos, os grupos de interesse, os movimentos sociais, a mídia etc. (SOUZA, 2007, p. 65-66).

Os críticos à abordagem DPP têm ainda uma segunda objeção, relativa à substituição de referências às políticas sociais, típicas do Estado de bem-estar social, pelas políticas públicas, que consideram novidade do gerencialismo. Essa dualidade, mais uma vez, estaria a sugerir as últimas como versões menos politizadas das primeiras. Mas esse entendimento não é corroborado pelos estudiosos do Estado 
de bem-estar, como Célia Lessa Kerstenetzky, que adota a expressão conjugada políticas públicas sociais, em capítulo com esse título, sem maior dificuldade:

O que são "políticas públicas"? Trata-se, genericamente, dos programas e ações desenvolvidos direta ou indiretamente pelo Estado, com vistas ao interesse público, ou, de modo mais estrito, dos princípios e propósitos que animam as decisões do Estado em várias áreas onde germina o interesse público, tal como estes se expressam em programas e ações. Mesmo nem sempre encontrando correspondência perfeita em normas constitucionais, as políticas públicas no mínimo não podem ferir esses preceitos e são, sob muitos aspectos, o braço executivo de direitos expressos na Constituição. [...]

Grosso modo, há dois paradigmas principais de política pública social: o primeiro a concebe como o conjunto de programas e ações governamentais voltadas para o alívio de situações de pobreza, privação e vulnerabilidade; o segundo enfatiza ações e programas em sua capacidade de resolver problemas sociais, atender necessidades e criar oportunidades. (KERSTENETZKY, 2014, p. 02, destaquei)

Celina Souza também entende haver uma distinção de foco entre os dois tipos, sem afastar a complementaridade entre ambas.

Enquanto estudos em políticas públicas concentram-se em responder questões como "por que" e "como", os estudos em políticas sociais tomam o processo apenas como "pano de fundo" e se concentram nas consequências da política, ou seja, o que a política faz ou fez. (SOUZA, 2007, p. 71)

Em trabalho mais recente, a autora passa a utilizar predominantemente a locução políticas públicas (SOUZA, 2018), na prática tomando ambas por sinônimas, como ocorre também em outros textos (CANOTILHO, 2008, p. 135). Em suma, as políticas públicas parecem ter passado por um alargamento semântico, passando a abarcar o sentido que originalmente era atribuído às políticas sociais.

O debate em torno do sentido político das políticas públicas, portanto, não se detém nas estruturas - o Estado, globalmente considerado (plano macroinstitucional), versus as políticas setoriais (plano meso-institucional) - ou nos qualificativos, políticas sociais versus políticas públicas. Considerando que o Estado, como organização abrangente, teve nos últimos quarenta anos 
profundamente alterados seus modos de ação e legitimação ${ }^{23}$, a instrumentalidade de cada política pública, assim como a resultante das várias políticas - seus produtos efetivos (outcomes) e o balanço de forças sociais envolvidas - é por onde se lê o sentido político geral de um governo.

\section{APlicAÇÕeS da ABORDAGEM DPP: MATRIZ DE MÉTODOS E VERTENTES DE ANÁLISE}

\section{Esquemas de representação em Direito e Políticas Públicas}

Do A abordagem DPP tem uma vocação aplicada, voltada à tradução do instrumentalismo em proposições juridicamente bem formuladas $\mathrm{e}$ adequadamente fundamentadas, com aptidão para a análise de problemas de concretos e contribuição para as soluções. Seu propósito é colaborar com a construção institucional do Estado brasileiro, na perspectiva democrática e da realização dos direitos fundamentais.

Diante da variedade das conexões possíveis entre direito e políticas públicas e seu caráter "labiríntico", uma estratégia metodológica possível é mapeá-las, identificando questões mais aptas à abordagem DPP. Parte-se de uma esquematização provisória, a ser posteriormente validada em pesquisas subsequentes. O mapa seria o guia da pesquisa, organizando um catálogo de referências a validar, com alimentação recíproca entre sistematização teórica e investigação empírica, na linha do quanto descrito na seção 2, acima.

Adotando o conceito de políticas públicas para o trabalho jurídico já muito debatido (BUCCI, 2013), o objeto da abordagem DPP é a ação governamental coordenada e em escala ampla, atuando sobre problemas complexos, a serviço de uma estratégia determinada, tudo isso conformado por regras e processos jurídicos. Seu objetivo é examinar os pontos de contato entre os aspectos políticos e jurídicos que cercam a ação governamental e como se promovem transformações jurídicoinstitucionais, ora por meio de uma aproximação realista e analítica, ora idealista e prescritiva (BUCCI, 2018). Aspecto complementar dessa abordagem é o destaque que se dá à perspectiva do Poder Executivo (BUCCI; DUARTE, 2017).

E aqui retomamos a discussão a respeito dos esquemas de simplificação necessários ao trabalho analítico. Cabe uma breve resenha de alguns esquemas de

\footnotetext{
${ }^{23}$ Subscrevo o entendimento de Celina Souza, para quem “(...) apesar de uma certa literatura argumentar que o papel dos governos tem sido encolhido por fenômenos como a globalização, a diminuição da capacidade dos governos de intervir, formular políticas públicas e de governar não está empiricamente comprovada. Visões menos ideologizadas defendem que apesar da existência de limitações e constrangimentos, estas não inibem a capacidade das instituições governamentais de governar a sociedade, apesar de tornarem a atividade de governar e de formular políticas públicas mais complexa." (SOUZA, 2007, p. 72). Em sentido similar, KERSTENETZKY e GUEDES, ainda que apontando para o crescimento da desigualdade e da pobreza em ritmo superior ao gasto social e ao esforço de redistribuição.
} 
representação produzidos na abordagem DPP, que têm permitido aprofundar o conhecimento sobre o papel dos elementos jurídicos na "grade de inteligibilidade das políticas públicas" (CAILOSSE, 2000, p. 46).

Inicialmente, propunha-se adotar como referências de método as categorias de instituições e processos, por serem recorrentes no âmbito da policy analysis. Quanto aos processos, indicava-se o estudo do processo governamental, processo de planejamento, processo orçamentário, processo legislativo, processo normativo do Poder Executivo e processo judicial (BUCCI, 2013).

Posteriormente, foi desenvolvido, como ferramenta didática, o Quadro de Referência de Políticas Públicas (BUCCI, 2015), com o propósito de servir de guia para o recorte de um programa de ação, destacando-o do entorno, com base nos seguintes elementos: i) nome oficial do programa de ação; ii) gestão governamental; iii) base normativa; iv) desenho jurídico-institucional (detalhado nos itens seguintes); v) agentes governamentais; vi) agentes não governamentais; vii) mecanismos jurídicos de articulação; viii) escala e público-alvo ; ix) dimensão econômico-financeira; $x$ ) estratégia de implantação; xi) funcionamento efetivo; xii) aspectos críticos do desenho jurídico-institucional. Aplicado principalmente por estudantes de Direito e Políticas Públicas, deu suporte a um razoável acervo de estudos, que demonstram tratar-se de framework útil para a aproximação do objeto e sua decomposição analítica.

Ainda assim, não é incomum encontrar pesquisadores inibidos diante da dificuldade de qualificar determinada ação governamental como política pública e, consequentemente, em dúvida sobre a pertinência da utilização do Quadro de Referência, o que se justifica pelo fato de que a maioria dos programas de ação governamental está insuficientemente institucionalizada. Ou, ao contrário, excessivamente formalizada em textos normativos carentes de efetividade. Essa indefinição, contudo, não deveria impedir o uso do Quadro. Se as suas variáveis forem úteis para "dissecar" a política pública, como procedimento heurístico, sua utilização, mesmo de maneira aproximada, permanece válida. Colocar lado a lado informações sobre a filiação partidária do gestor governamental, a estratégia jurídica de implantação do programa e a escala pretendida, por exemplo, pode proporcionar uma perspectiva reveladora para a compreensão de pontos que de outra maneira escapariam à percepção.

Mas a prática do Quadro de Referência revelou uma insuficiência importante, que é voltar-se apenas às políticas públicas razoavelmente institucionalizadas, isto é, assentadas sobre uma base normativa que não seja um mero amontoado de normas, mas funcione como elemento de organização sistemática e efetiva da ação governamental, capaz de orientar comportamentos de agentes públicos e privados no sentido das transformações desejadas. Como dito, a racionalidade do Quadro supõe uma política pública completa ou pelo menos em processo de institucionalização, com seus contornos identificáveis. Ele não se presta, todavia, como suporte cognitivo para problemas cujas soluções ainda não estejam 
estruturadas. Se utilizarmos a figura do ciclo de políticas públicas, os temas que não logram entrar na agenda política carecem de institucionalização mínima. Nesses casos, o Quadro de Referência é, de fato, inadequado. É o que ocorre, por exemplo, no caso da política penitenciária no Brasil, que mais corretamente se poderia chamar de "não-política", diante da escassez de racionalidade das medidas governamentais que vem sendo adotadas no campo nas últimas décadas. Quando se examina a ADI 347 - a petição inicial é mais reveladora que a decisão judicial está-se diante de um caso em que disposições jurídicas que vão desde os tratados internacionais de direitos humanos, a Constituição, a legislação de execução penal, relatórios de Comissão Parlamentar de Inquérito etc. são suficientes a disciplinar a solução da matéria, mas essas têm sido reiteradamente descumpridas. Para compreender analiticamente essa limitação, foi concebido o Quadro de Problemas de Políticas Públicas ${ }^{24}$.

Além desses, há também o quadro de análise proposto por Diogo Coutinho baseado em quatro papéis e tarefas para o direito e seus operadores em políticas públicas: "apontar fins e situar as políticas no ordenamento (direito como objetivo), criar condições de participação (direito como vocalizador de demandas), oferecer meios (caixa de ferramentas) e estruturar arranjos complexos que tornem eficazes essas políticas (direito como arranjo institucional)" (COUTINHO, 2013, p. 194), bastante utilizado pelos pesquisadores em Direito.

\section{Matriz de métodos, suas vertentes, e a renovação da dogmática jurídica pelas políticas públicas}

Da vasta produção de pesquisas e estudos em Direito e Políticas Públicas ${ }^{25}$ podem ser identificadas algumas vertentes mais promissoras. Essas vertentes, que não excluem, mas complementam os esquemas acima referidos, levam em conta as comunidades epistêmicas ${ }^{26}$, isto é, os pesquisadores e operadores do direito mais diretamente interessados em uma gama determinada de problemas, que no âmbito da prática jurídica configuram a chamada "comunidade dogmática" (CALSAMIGLIA, 1990, p. 78). Seriam, por exemplo, os administrativistas, os processualistas, ou, em outro plano, a comunidade da educação, a da saúde, a da assistência e assim por diante.

O mais adequado para descrever o conjunto de vertentes seria uma matriz de métodos, uma vez que há incontáveis peculiaridades em cada uma delas. Cada vertente não exclui necessariamente as demais. Retorna-se ao ponto de partida deste artigo, que ao reconhecer a dispersão de ângulos de visão sobre o fenômeno

\footnotetext{
${ }^{24}$ Ver artigo de Isabela Ruiz e Maria Paula Dallari Bucci neste dossiê.

${ }^{25}$ Um retrato mais fiel da abordagem reclamaria uma revisão bibliográfica ampla e sistemática sobre a produção que já se acumula sobre a temática das políticas públicas em Direito, o que se deixa de fazer neste momento em virtude da escassez de tempo e condições materiais.

${ }^{26}$ Sobre esse ponto e a questão da interdisciplinaridade na abordagem DPP, ver artigos de Ester Rizzi e Gustavo Bambini e Emiliano Brunet, neste dossiê.
} 
das políticas públicas, assume a fragilidade intrínseca das propostas de agregação metodológica, que só sua aplicação será capaz de mitigar.

Também impactam as aplicações do método dificuldades específicas da prática de pesquisa em DPP, entre elas a interdisciplinaridade e o imbricamento da atividade acadêmica com o exercício profissional.

Quanto à interdisciplinaridade, não é simples compatibilizar as diferentes fontes de conhecimento sobre as políticas públicas. Partindo-se do pressuposto de que essas não se reduzem aos aspectos jurídicos, outros elementos (como dados estatísticos por exemplo) têm que ser buscados em repertórios próprios, cuja linguagem e autores escapam ao universo tradicional da pesquisa em Direito. Para evitar o sincretismo metodológico ${ }^{27}$, as informações e fundamentos obtidos segundo cada uma das visões disciplinares deveriam ser apresentados de forma apropriada, e as conexões, demonstradas em seguida, como produto de operação cognitiva explícita de aproximação entre os dois campos. A parte jurídica da pesquisa deve apresentar as fontes primárias (normas, decisões e documentos oficiais) com precisão técnica e informativa, relatando e documentando a política pública para fundamentar a análise crítica. Do mesmo modo que uma pesquisa empírica apresenta os dados antes de discutir os resultados, na pesquisa em DPP é preciso que a fundamentação propriamente jurídica possa ser lida e compreendida de modo amplo, se possível também por leitores das disciplinas afins, previamente à discussão crítica. Esse cuidado previne a apreensão equivocada da interdisciplinaridade, em que análises com pouca substância jurídica se combinam com algum referencial teórico das áreas afins, como ciência política, sociologia ou economia, também de maneira aligeirada. Evidentemente, o tipo de trabalho oposto, que resume a apresentação da política pública à descrição do direito positivo, também não se compatibiliza com a abordagem DPP, na medida em que carece de conexões fundamentadas com fatores determinantes das esferas política ou social.

Outro aspecto a considerar é que a formação jurídica é assumidamente profissionalizante e o pesquisador em direito, com frequência, é um profissional que lida com o conhecimento aplicado e busca aprofundamento teórico para sua atividade ${ }^{28}$. A profissão faz o pesquisador, mais do que o inverso. Aqui se combina o prescritivo com o analítico, geralmente com dominância do primeiro sobre o segundo.

Mas, na linha de Calsamiglia, a abordagem DPP não menospreza essa condição, apenas a reconhece como peculiaridade do campo jurídico, o que demanda compreender também o processo de produção das práticas jurídicas, a chamada dogmática jurídica, e suas relações com as políticas públicas, conforme se verá adiante.

\footnotetext{
${ }^{27}$ Adotar "teorias incompatíveis, como se compatíveis fossem". (AFONSO DA SILVA, 2003, p. 625)

${ }^{28}$ Ver artigo de Patrícia Ulson Werner, neste dossiê.
} 


\subsection{Vertente do direito material (ou organização)}

A primeira vertente a explorar refere-se ao direito material, cujo foco está na institucionalização dos direitos, em especial os direitos sociais, com uma nova promessa de efetividade entre nós, desde a Constituição de 1988. Aqui, a abordagem DPP parece proporcionar ganhos analíticos significativos, dada a inequívoca complexidade da provisão de serviços públicos e da regulação de serviços privados ligados aos direitos sociais, ainda mais sob o regime democrático. Nas últimas décadas, cresceram em volume e qualidade os estudos específicos sobre direitos da educação, saúde, habitação, mobilidade urbana, cultura, ciência e tecnologia etc. Na mesma linha, cresceu também a especialização em torno dos direitos da infra-estrutura, tais como transporte, energia, telecomunicações etc. Cada um desses direitos ou temas vem sendo estudado por uma comunidade epistêmica razoavelmente definida. Em outras palavras, há grupos de especialistas em educação, saúde, segurança, cidades, infra-estrutura, cada um ciente de questões jurídicas que lhes afetam de maneira particular e suas injunções com aspectos de gestão e financiamento, movimentos sociais, demandas legislativas e políticas e assim por diante. $\mathrm{O}$ conhecimento e técnicas específicas justifica falar-se em direito $d a$ educação, da saúde, da energia, conforme ensinava Fábio Comparato em suas aulas. O que permite agrupar essas comunidades nesta vertente metodológica é a ênfase nos resultados de cada política e por isso a tônica recai sobre a dimensão organizativa e institucional associada a cada um dos direitos ou temas.

Tema especialmente relevante nessa vertente são os mecanismos de articulação federativa, até em virtude das competências comuns estabelecidas no art. 23 da CF. Um caso notável de aprendizagem institucional é a criação e estruturação dos sistemas de direitos sociais no Brasil, a partir do Sistema Único de Saúde, emulado no Sistema Único da Assistência Social e no tardio Sistema Único de Segurança Pública $^{29}$. Essas experiências, que enfeixam uma multiplicidade de soluções, tais como repasses fundo a fundo aplicados à saúde e à assistência, normas operacionais, participação de gestores estaduais e municipais em instâncias decisórias nacionais ("bipartites" ou "tripartites"), representam uma tecnologia jurídica e de gestão que viabiliza autênticas políticas de Estado, na medida em que institucionaliza práticas - racionais, democráticas e garantidoras de direitos - que perduram para além das gestões governamentais. $O$ que não significa, evidentemente, que tais práticas não possam ser alvo de ataques ou esvaziamento por governos que não prezam seu caráter civilizatório.

Juntamente com os mecanismos de articulação federativa entre entes públicos e de pactuação entre públicos e privados ${ }^{30}$, expedientes de participação social e de usuários, que ampliam a experiência dos conselhos, esboçam possibilidades de

\footnotetext{
${ }^{29}$ Clarice Seixas Duarte, em artigo neste dossiê, investiga os entraves para a organização do Sistema Nacional de Educação.

${ }^{30}$ Tais como as figuras em que se diversificaram os antigos convênios, como os contratos de gestão, os termos de parceria, os termos de colaboração e de fomento e os acordos de colaboração (MÂNICA).
} 
institucionalização jurídica de redes de políticas públicas, que caracterizam os entrelaçamentos de múltiplos de pólos de ação e decisão, descritas há décadas na Análise de Políticas Públicas (ADAM; KRIESI, 2007), mas ainda carentes de tradução jurídica. Juntamente com temas como o desenho ou modelagem de instituições ou arquitetura jurídica de políticas públicas, referidas com frequência, mas demandando fundamentação teórica, esses temas, se tratados de maneira sistemática, a partir de situações reais, alargarão as fronteiras do direito público.

Isso se combina com a importância conferida na abordagem DPP ao processo legislativo e aos processos de formação do direito, em geral. Trata-se da identificação das forças políticas em disputa e como seus movimentos se traduzem em normas jurídicas. Sem descuidar da autonomia do direito em face da política, procura-se "compreender e aceitar as contingências que cercam o ciclo de vida normativo [...] atribuindo relevância e dignidade às vicissitudes de sua formulação e implementação" (DE PAULA, 2016, p. 79). Desenvolve-se também a Legística ou Ciência da Legislação, antecipada por Morand, no Brasil, num movimento próprio (SOARES, 2007; SALINAS, 2013; DE PAULA, 2016).

\subsection{Vertente do controle}

A segunda vertente centra-se no controle, que se expandiu muito no Brasil desde a Constituição de 1988, a ponto de a Lei n. 13.655, de 2018 (LINDB), ter instituído a denominada "esfera controladora". Essa vertente se baseia na fiscalização do exercício de responsabilidades legais e procedimentos devidos, o que influi direta ou indiretamente sobre a implementação e avaliação de políticas públicas. $O$ controle se dá mediante iniciativas e decisões do Poder Judiciário, Ministério Público, Defensoria Pública, Advocacia Pública, além de órgãos como Tribunais de Contas, controladorias e afins. Nos últimos anos, na prática se constituiu uma comunidade profissional e epistêmica própria, em torno do tema do controle. Diferentemente da primeira vertente, nessa é menor a ênfase ao aspecto organizativo e funcional das políticas públicas, predominando o foco sobre as condutas de agentes públicos, precipuamente.

A vertente do controle segue crescendo. No campo da produção legislativa, a busca de disciplina jurídica mais clara deu origem a projeto sobre o "processo especial para o controle e intervenção em políticas públicas pelo Poder Judiciário" (PL 8058/2014, baseado em projeto da saudosa profa. Ada Pellegrini Grinover) ${ }^{31}$, e o projeto que exige avaliação de impacto legislativo em proposições legislativas que instituam políticas públicas (PLS 488/2017). Esse último, se aprovado, diga-se, representará mais uma investida das esferas de controle sobre a de organização das políticas públicas, burocratizando a elaboração de políticas abrangentes, como teria

\footnotetext{
${ }^{31}$ Depois do arquivamento na última legislatura, há notícia da retomada da tramitação do projeto no Congresso Nacional, em 2019. Agradeço a Pedro Rizzo pela informação.
} 
ocorrido, por exemplo, com o Plano Nacional de Educação, que jamais teria existido se dependesse dessa providência.

A LINDB, ao tratar expressamente das políticas públicas (art. 2232), sob a justificativa de reforço à segurança jurídica (MARQUES NETO, 2019) explicita a necessidade de defesa de agentes públicos e privados em face da atuação alargada dos órgãos de controle, com apelo aos conceitos jurídicos indeterminados de que se vale a lei. É interessante refletir sobre a multidisciplinariedade das políticas públicas, a propósito dessa lei. Pois se ela movimentou intensamente a comunidade jurídica, disparando a produção de imensa quantidade de artigos de análise e debate doutrinário, passou relativamente despercebida no "campo de públicas", a despeito do interesse que há na área sobre a judicialização e controles de políticas públicas.

As considerações de método de ordem geral, feitas na seção 2, valeriam aqui no sentido da construção de estratégias convergentes e coordenadas de controle pelos vários órgãos com competência sobre a matéria, para efeitos de escala ampla, o que é traço característico das políticas públicas.

\subsection{Vertente das disciplinas}

Finalmente, a terceira vertente diz respeito às disciplinas jurídicas com relações com as políticas públicas, tais como Direito Administrativo, Constitucional, Financeiro, Processual, Internacional, Teoria Geral do Estado, Teoria Geral do Direito e outras. Esse recorte se apoia sobre comunidades bem estabelecidas nas estruturas acadêmicas das universidades e programas de pós-graduação e pesquisa, considerando que o conhecimento canônico é o disciplinar ${ }^{33}$. É a elas que cabe internalizar no sistema conceitual do direito as inovações trazidas pela abordagem DPP mas demais vertentes ou, reversamente, conceber formulações conceituais que, desdobradas em proposições e procedimentos, serão experimentadas nas práticas de organização e controle de que ambas se ocupam.

A abordagem DPP à margem das disciplinas tem grande potencial crítico, mas não é capaz de organizar categorias inovadoras para a operação do direito, de forma estruturada. Esse papel sempre coube à dogmática jurídica.

E não por acaso, a dogmática jurídica é considerada um dos principais "esquemas de simplificação" do direito, segundo Alberto Calsamiglia:

A dogmática é um conhecimento que pretende apresentar o material jurídico disperso em um esquema simplificado. Os conceitos elaborados pela dogmática servem para qualificar os fatos e para

\footnotetext{
${ }^{32}$ Art. 22. Na interpretação de normas sobre gestão pública, serão considerados os obstáculos e as dificuldades reais do gestor e as exigências das políticas públicas a seu cargo, sem prejuízo dos direitos dos administrados.

${ }^{33}$ Maurício Pietrocola, comunicação sobre Metodologia e Interdisciplinaridade, em Semana Pedagógica 2019, Faculdade de Direito da Universidade de São Paulo. (PIETROCOLA, ALVES FILHO e PINHEIRO)
} 
observar o mundo do direito a partir de uma perspectiva determinada. O jurista, o juiz e o advogado lêem o mundo dos fatos, da lei e da resolução dos conflitos mediante a rede conceitual elaborada pela dogmática. Nesse sentido, a dogmática é uma escala intermediária entre a lei e os fatos. [...] Mas a função da dogmática não é apenas cognoscitiva. Um de seus objetivos é proporcionar critérios ao intérprete do direito para a resolução de casos difíceis. O caráter híbrido desse saber - amálgama de descrição e prescrição - criou problemas de justificação a seus cultores, por que a dogmática não se limita a descrever seu objeto, mas faz parte dele. [...] a dogmática cumpre um papel ordenador e racionalizador, $[\ldots]$ quanto menos desenvolvida, mais imprevisível será a decisão dos tribunais. (CALSAMIGLIA, 1990, p. 79, destaquei)

Em síntese, valendo-se dessa capacidade de simplificação, a renovação da dogmática jurídica seria um dos caminhos para o desenvolvimento da abordagem DPP.

Um problema dessa associação estaria na subversão do sentido tradicional de dogmática jurídica, domínio do formalismo jurídico por excelência, e quebrá-lo foi, aliás, o que justificou a abertura dos juristas para políticas públicas ${ }^{34}$. O problema da dogmática é que ela pode ser, realmente, dogmática, isto é, impermeável a influências de outros campos. (Mas é aí, talvez, que reside a sua força.)

Uma segunda crítica é o fato de que a noção de dogmática se desenvolveu no bojo do processo de separação entre direito e política. Seria, portanto, heterodoxo pretender construir uma dogmática, como esquema de simplificação jurídica, para incorporar ao direito as variações próprias das políticas públicas. Isso seria confundir a dogmática com outra atividade, a política jurídica - "quem critica as normas não trabalha no seio da dogmática, mas no campo da política jurídica" (CALSAMIGLIA, 1990, p. 76).

Mas a conexão realizada por Tércio Sampaio Ferraz Jr. entre a dogmática e a tecnologia jurídica - além de nos remeter à tecnologia de políticas públicas aventada por Diogo Coutinho $(2013 ; 2016)$ - indica uma leitura política da dogmática que se aproxima do que estamos sugerindo:

\footnotetext{
34 “Os teóricos do direito não desenvolveram até pouco tempo atrás senão atividades de uma tecnologia jurídica, de racionalização da técnica jurídica e mais precisamente atividades de dogmática jurídica consistentes em organizar, na forma de um dogma as diferentes regras jurídicas editadas pelos poderes públicos, se esforçando por estabelecer uma apresentação ordenada, sistemática e coerente, se ocupando de dar às disposições jurídicas em vigor comentários interpretativos judiciosos e racionais, explicitando sua abrangência, suas potencialidades, eliminando e reduzindo seus defeitos aparentes, suas obscuridades, suas lacunas, suas contradições etc. Essa atividade de "doutrina jurídica" ainda é largamente dominante hoje, notadamente no plano universitário." (P. Amselek, citado por CAILLOSSE, 2000, p. 46).
} 
"[...] a ciência dogmática cumpre as funções típicas de uma tecnologia. Sendo um pensamento conceitual, vinculado ao direito posto, a dogmática pode instrumentalizar-se a serviço da ação sobre a sociedade. [...] A tecnologia jurídica atual força a vida social, ocultando-a, ao manipulá-la, ao contrário da ciência prática da Antiguidade, que se prostrava, com humildade, diante da natureza das coisas. Por exemplo, se, no passado, seria inconcebível imaginar-se que o instituto jurídico do matrimônio pudesse ser aplicado às relações homossexuais, na atualidade, através da manipulação conceitual, esta hipótese adquire viabilidade./ O saber dogmático contemporâneo, nesse sentido [...] uma tecnologia em princípio semelhante às tecnologias industriais, $[\ldots]$. (FERRAZ Jr., 1994, p. 87-88, grifo no original)

A noção do direito como tecnologia implica considerar os modos de produção do saber e seu uso em formas aplicadas. Em outras palavras, dotar o instrumentalismo jurídico de uma dimensão executiva, incluindo os problemas de poder subjacentes à escolha das direções e dos instrumentos e estratégias jurídicas. Uma sistematização teórica adequada das práticas jurídicas em políticas públicas lhes conferiria não apenas racionalidade, mas legitimação, e com isso potencializaria os seus efeitos.

No estágio atual da abordagem DPP, muita reflexão ainda deverá ser feita para encontrar caminhos frutíferos. As iniciativas de pesquisa compõem a massa crítica da qual se poderá extrair, mediante um trabalho teórico-conceitual, a sistematização teórica partindo da observação de regularidades, das figuras jurídicas mais afeitas a expressar os problemas complexos, gerados no contexto do Estado social contemporâneo, armadas numa rede conceitual própria à operação do direito. Assim num balanço entre conhecimento teórico e aplicado, o método poderia contribuir para uma compreensão das aplicações mais fecundas para um trabalho de construção institucional.

\section{REFERÊNCIAS}

ADAM, Silke; KRIESI, Hanspeter. The network approach. In: SABATIER, Paul. (org.). Theories of the policy process. Colorado: Westview Press, 2007.

AFONSO DA SILVA, Virgílio. Princípios e regras: mitos e equívocos acerca de uma distinção Interpretação constitucional. Revista Latino-Americana de Estudos Constitucionais, 2003, p. 607-630. 
AFONSO DA SILVA, Virgílio. Interpretação constitucional e sincretismo metodológico. In: AFONSO DA SILVA, Virgílio (org.). Interpretação constitucional. São Paulo: Malheiros, p. 115-143.

ALMEIDA, Maria Hermínia Tavares de. Prefácio. In: HOCHMAN, Gilberto; ARRETCHE, Marta; MARQUES, Eduardo (orgs.). Políticas públicas no Brasil. Rio de Janeiro: Editora Fiocruz.

ARRETCHE, Marta. Democracia e redução da desigualdade econômica no Brasil. A inclusão dos outsiders. Revista Brasileira de Ciências Sociais, 2018, v. 33, n. 96, p. 1-23.

AUER, Andreas et al. Avant-propos. In: AUER, Andreas et al. (orgs). Aux confins du droit: essais en l'honneur du Professeur Charles-Albert Morand. Munich: Helbing et Lichtenhahn, 2001.

BERCOVICI, Gilberto O Estado desenvolvimentista e seus impasses: uma análise do caso brasileiro. Boletim de Ciências Económicas. Faculdade de Direito da Universidade de Coimbra, 2004, v. XLVII, p. 149-180.

BERCOVICI, Gilberto. Planejamento e políticas públicas: por uma nova compreensão do papel do Estado. In: BUCCI, Maria Paula Dallari (org.). Políticas públicas: reflexões sobre o conceito jurídico. São Paulo: Saraiva, 2006, p. 143-162.

BERCOVICI, Gilberto. As origens do direito econômico: homenagem a Washington Peluso Albino de Souza. Rev. Fac. Direito UFMG, 2013, p. 253-263.

BERCOVICI, Gilberto; MASSONETTO, Luis Fernando. A constituição dirigente invertida: a blindagem da constituição financeira e a agonia da constituição econômica. Separata do Boletim de Ciências Econômicas. Faculdade de Direito da Universidade de Coimbra, 2006, v. XLIX.

BONAVIDES, Paulo. Do país constitutional ao país neocolonial. A derrubada da Constituição e a recolonização pelo golpe de Estado institucional. 4a ed. São Paulo: Revista dos Tribunais, 2009.

BRUNET, Emiliano R. Sobre a abordagem acadêmica de políticas públicas em um curso de graduação em direito: contribuição para um programa. REI-Revista Estudos Institucionais, 2019, vol. 5, n. 3. 
BUCCI, Maria Paula Dallari. Fundamentos para uma teoria jurídica das políticas públicas. São Paulo: Saraiva, 2013.

BUCCI, Maria Paula Dallari. Quadro de referência de uma política pública. Primeiras linhas para uma abordagem jurídico-institucional (republicado em Colunistas Direito do Estado, 2015. Disponível em $<$ http://www.direitodoestado.com.br/colunistas/maria-paula-dallaribucci/quadro-de-referencia-de-uma-politica-publica-primeiras-linhas-de-umavisao-juridico-institucional>. Acessado em 22 nov. 2019.

BUCCI, Maria Paula Dallari. A Teoria do Estado entre o jurídico e o político. In: BUCCI, Maria Paula Dallari; GASPARDO, Murilo (orgs.). Teoria do Estado: sentidos contemporâneos. São Paulo: Saraiva, 2018, p. 27-74.

BUCCI, Maria Paula Dallari; COUTINHO, Diogo. Arranjos jurídico-institucionais da política de inovação tecnológica: uma análise baseada na abordagem de direito e políticas públicas. In: COUTINHO, Diogo; FOSS, Maria Carolina; MOUALEM, Pedro Salomon (orgs.) Inovação no Brasil: avanços e desafios jurídicos e institucionais. São Paulo: Blucher, 2017, p. 313-340. Disponível em $<$ https://openaccess.blucher.com.br/article-details/12-20820>. Acessado em: 23 nov. 2019.

BUCCI, Maria Paula Dallari; DUARTE, Clarice Seixas. Judicialização da saúde: a visão do Poder Executivo. São Paulo: Saraiva, 2017.

CAILLOSSE, Jacques. Morand Charles-Albert, Le droit néo-moderne des politiques publiques. Droit et société, 1999, n. 42-43, p. 511-519. Disponível em <http://www.persee.fr/doc/dreso_0769-3362_1999_num_42_1_1762>. Acesso em 06 jun. 2016.

CAILLOSSE, Jacques. Le droit comme méthode? Réflexions depuis le cas français. In: RENARD, Didier; CAILOSSE, Jacques; BÉCHILLON, Denys de. L'analyse des politiques publiques aux prises avec le droit. Paris: LGDJ, 2000, p. 27-68.

CALSAMIGLIA, Alberto. Introducción a la Ciencia Jurídica. 3a ed. Barcelona: Editorial Ariel S.A, 1990.

CANOTILHO, J. J. Gomes. Estado pós-moderno e Constituição sem sujeito. In: CANOTILHO, J. J. Gomes (org.). "Brancosos" e interconstitucionalidade. 
Itinerários dos discursos sobre a historicidade constitucional. 2a ed. Coimbra: Almedina, 2008.

CHILVARQUER, Marcelo. Aplicando o quadro de referência para análise jurídica de políticas públicas: a implementação do Programa Minha Casa, Minha Faixa 1 no Município de São Paulo. REI-Revista Estudos Institucionais, v. 5, n. 3, 2019.

CLUNE, William H. A Political Model of Implementation and Implications of the Model for Public Policy, Research, and the Changing Roles of Law and Lawyers. Iowa Law Review, v. 69, 1983, p. 47-125.

CLUNE, William H. Law and Public Policy: Map of an Area. Southern California Interdisciplinary Law Journal, v. 2, 1993, p. 01-39.

CLUNE, William. H. Legal Disintegration and a Theory of the State. German Law Journal, v. 12, 2011, p. 186-205.

COMPARATO, Fábio Konder. O indispensável Direito Econômico. Revista dos Tribunais, v. 101, n. 923, 2012, p. 37-52.

COUTINHO, Diogo. O direito nas políticas públicas. In: MARQUES, Eduardo; FARIS, Carlos Aurélio Pimenta de (orgs.). A política pública como campo multidisciplinar. São Paulo: Ed. Unesp/Rio de Janeiro: Editora Fiocruz, 2013, p. 181-200.

COUTINHO, Diogo. O Direito Econômico e a construção institucional do desenvolvimento democrático. REI-Revista Estudos Institucionais, vol. 2, n. 1, p. 214-262.

DE PAULA, Felipe. Avaliação legislativa no Brasil: limites e possibilidades. Tese de doutorado. 2016. São Paulo: Universidade de São Paulo, Faculdade de Direito.

DUARTE, Clarice Seixas. Os entraves à institucionalização do SNE: uma análise a partir da metodologia de pesquisa jurídica em políticas públicas. REI-Revista Estudos Institucionais, v. 5, n. 3, 2019.

DRAIBE, Sônia M. Estado de bem-estar, desenvolvimento econômico e cidadania: algumas lições da literatura contemporânea. In: HOCHMAN, Gilberto; 
ARRETCHE, Marta; MARQUES, Eduardo (orgs.). Políticas públicas no Brasil. Rio de Janeiro: Editora Fiocruz, 2007.

ESPING-ANDERSEN, Gosta. As três economias políticas do welfare state. Lua Nova, n. 24, 1991, p. 85-116.

EWALD, François. The concept of social law. In: TEUBNER, Gunther (ed.). Dilemmas of law in the welfare state. New York/Berlin: Walter de Gruyter, 1988.

FARAH, Marta. Análise de políticas públicas no Brasil: de uma prática não nomeada à institucionalização do "campo de públicas". Revista de Administração Pública, v. 50, n. 6, 2016, p. 959-979.

FARRANHA, Ana; SOARES, Paulo; MIRANDA, Juliana. Public policy analysis and the law: a teaching experience and a research methodology. Institut de Recerca TransJus. Universitat de Barcelona. TransJus Working Papers Publications ISSN 2462-263X Working Paper N. 3/2019.

FERRAZ Jr, Tércio Sampaio. Introdução ao Estudo do Direito. Técnica, Decisão, Dominação. 2a ed. São Paulo: Atlas, 1994.

FLUECKIGER, Alexandre. (Re)faire la loi. Traité de légistique à l'ère du droit souple. Berna: Stämpfli, 2019. Disponível em: <http://archive-ouverte.unige.ch>. Acesso em: 23 nov. 2019.

FREY, Klaus. Políticas públicas: um debate conceitual e reflexões referentes à prática da análise de políticas públicas no Brasil. Planejamento e Políticas Públicas, n. 21, 2000, p. 211-259.

GASPARDO, Murilo. Pesquisa empírica e Teoria do Estado: a experiência da avaliação legislativa da Emenda do Programa de Metas. Revista de Estudos Empíricos em Direito (Brazilian Journal of Empirical Legal Studies), v. 5, n. 3, 2018, p. 30-49.

GRIN, Eduardo. Regime de Bem-estar Social no Brasil: Três Períodos Históricos, Três Diferenças em Relação ao Modelo Europeu Social-democrata. Cadernos Gestão Pública e Cidadania, v. 18, n. 63, 2013. 
HADDAD, Frederico. A pertinência da abordagem de Direito e Políticas Públicas ao estudo da política urbana no Brasil: o exemplo da pesquisa jurídica sobre as vias urbanas e sua função social. REI-Revista Estudos Institucionais, v. 5, n. 3, 2019.

JORGE, Ighor Rafael de. Processo de elaboração normativa e políticas públicas: a visão jurídico-institucional da política de formação de professores da educação básica. REI-Revista Estudos Institucionais, v. 5, n. 3, 2019.

JOUANJAN, Olivier; MAULIN, Eric. La théorie de l'État entre passé et avenir. Journées en l'honneur de Carré de Malberg. Revue de droit politique, n. 8, setembro 2012. Disponível em: <http://juspoliticum.com/article/Introduction-Latheorie-de-l-Etat-entre-passe-et-avenir-Journees-en-l-honneur-de-Carres-deMalberg-549.html >. Acessado em: 07 out. 2019.

KENNEDY, Duncan. The political significance of the structure of the Law School curriculum. Seton Hall Law Review, v. 14, n. 1, 1983, p. 01-16.

KERSTENETZKY, Célia Lessa. Políticas públicas sociais. Centro de Estudos sobre Desigualdade e Desenvolvimento-CEDE. Texto para discussão n. 92, fev 2014.

KERSTENETZKY, Celia Lessa; GUEDES, Graciele Pereira. O Welfare State resiste? Desenvolvimentos recentes do estado social nos países da OCDE. Ciência \& Saúde Coletiva, v. 23, n. 7, 2018, p. 2095-2106.

KREIS, Anthony Michael; CHRISTENSEN, Robert K. Law and public policy. The Policy Studies Journal, v. 41, n. S1, 2013, p. S38-52.

LOWI, Theodore J. American business, public policy, case-studies and political theory. World Politics, v. 16; 1964. Republicado em Public policy theories, models and concepts. An anthology (Daniel Mc Cool, org.). New Jersey: Prentice Hall.

LOWI, Theodore J. Four Systems of Policy, Politics, and Choice. Public Administration Review, v. 32, n. 4, 1972, p. 298-310.

MACHADO, Maira Rocha $\mathrm{O}$ estudo de caso na pesquisa em direito. In: MACHADO, Maíra Rocha (org.). Pesquisar empiricamente o direito. São Paulo: Rede de Estudos Empíricos em Direito, 2017. 
MALHEIROS, Rafael Taranto; DUARTE, Clarice Seixas. A dimensão jurídicoinstitucional da política pública da regularização fundiária urbana de interesse social e a busca de sua efetividade. REI-Revista Estudos Institucionais, v. 5, n. 3, 2019.

MÂNICA, Fernando Borges. Objeto e natureza das parcerias sociais: limites para a execução privada de tarefas estatais e o novo direito do terceiro setor. In: MOTTA, Fabrício; MÂNICA, Fernando Borges; OLIVEIRA, Rafael Arruda (coords.). Parcerias com o terceiro setor: as inovações da Lei n. 13.019/14. Belo Horizonte: Fórum, 2018.

MARQUES NETO, Floriano P.A. Comentários à Lei n. 13.655/2018. Belo Horizonte: Fórum, 2019.

MARQUES, Eduardo. In: MARQUES, Eduardo; FARIS, Carlos Aurélio Pimenta de (orgs.). A política pública como campo multidisciplinar. São Paulo: Editora Unesp/Rio de Janeiro: Editora Fiocruz, 2019.

MARQUES, Eduardo; FARIA, Carlos Aurélio. A política pública como campo multidisciplinar (coletânea). São Paulo: Editora Unesp/Rio de Janeiro: Editora Fiocruz, 2013.

MORAND, Charles-Albert. Le droit neo moderne des politiques publiques. Paris: LGDJ, 1999.

OSTROM, Elinor. Institutional rational choice: an assessment of the institutional analysis and development framework. In: SABATIER, Paul (org.). Theories of the policy process. Colorado: Westview Press, 2007.

OSTROM, Elinor. El gobierno de los bienes comunes. La evolución de las instituciones de acción colectiva. 2a ed. em espanhol. Tradução e revisão técnica de Leticia Merino Pérez. México: Fondo de Cultura Económica/Universidad Nacional Autónoma de México, 2011.

PIETROCOLA, Maurício; ALVES FILHO, José de Pinho; PINHEIRO, Terezinha F. Prática interdisciplinar na formação disciplinar de professores de ciências. Investigações em Ensino de Ciências (Online), v. 8, 2003, p. 01-21. Disponível em: <http://www.if.ufrgs.br/public/ensino/vol8/n2/v8_n2_a3.html\#[2]>. Acesso em: 28 out. 2019. 
QUIRINO, Carina de Castro. Regulação comportamental: justificação, diagnósticos e aplicação em políticas públicas no Brasil. Tese de doutorado. 2019. Universidade Estadual do Rio de Janeiro (UERJ).

RIBEIRO, Ivan César. Políticas públicas e teorias de Estado: o papel das teorias de médio alcance. REI-Revista Estudos Institucionais, v. 5, n. 3, 2019.

RIZZI, Ester Gammardella; BAMBINI, Gustavo. A tarefa de ensinar direito no campo das políticas públicas. REI-Revista Estudos Institucionais, v. 5, n. 3, 2019.

RUIZ, Isabela; BUCCI, Maria Paula Dallari. Quadro de problemas de políticas públicas: uma ferramenta para análise jurídico-institucional. REI-Revista Estudos Institucionais, v. 5, n. 3, 2019.

SABATIER, Paul. Introduction: the need for better theories. In: SABATIER, Paul (org.). Theories of the policy process. Colorado: Westview Press, 2007.

SALINAS, Natasha Schmitt Cacia. Avaliação legislativa no Brasil: apontamentos para uma nova agenda de pesquisa sobre o modo de produção das leis. Revista Brasileira de Políticas Públicas, v. 3, n. 2, 2013, p. 229-250.

SANTOS, Wanderley Guilherme. Cidadania e justiça. A política social na ordem brasileira. Rio de Janeiro: Editora Campus Ltda, 1979.

SOARES, Fabiana de Menezes. Legística e desenvolvimento: a qualidade da lei no quadro de otimização de uma melhor legislação. Revista da Faculdade de Direito da UFMG, n. 50, jan.- jul., 2007, p. 124-142.

SOUZA, Celina. Estado da arte da pesquisa em políticas públicas. In: HOCHMAN, Gilberto; ARRETCHE, Marta; MARQUES, Eduardo (orgs.). Políticas públicas no Brasil. Rio de Janeiro: Fiocruz, 2007.

SOUZA, Celina. Coordenação de políticas públicas. Brasília: ENAP, 2018.

SOUZA, Matheus Silveira de; BUCCI, Maria Paula Dallari. O estado da arte da abordagem direito e políticas públicas em âmbito internacional: primeiras aproximações. REI-Revista Estudos Institucionais, v. 5, n. 3, 2019. 
TOLEDO, Carlos José Teixeira de. O neoinstitucionalismo histórico como método de análise jurídica de políticas públicas: o estudo da trajetória da política de carreira docente. REI-Revista Estudos Institucionais, v. 5, n. 3, 2019.

VALENTE, Sérgio Ruy David Polimeno. Direito e políticas públicas: uma visão jurídico-institucional sobre o caso do saneamento básico no Brasil. REI-Revista Estudos Institucionais, v. 5, n. 3, 2019.

WERNER, Patricia Ulson Pizarro. A abordagem Direito e Políticas Públicas como ferramenta de aprimoramento das Instituições Jurídicas: qualidade organizacional, sistematização de dados e aperfeiçoamento das relações interinstitucionais. REIRevista Estudos Institucionais, v. 5, n. 3, 2019. 